\title{
Study on the effectiveness of PNS and LS superplasticizers in air

\author{
lime-based mortars
}

doi:10.1016/j.cemconres.2015.12.006

Available online 14 January 2016

M. Pérez-Nicolás ${ }^{\mathrm{a}}$, A. Duran ${ }^{\mathrm{a}}$, I. Navarro-Blasco ${ }^{\mathrm{a}}$, J.M. Fernández ${ }^{\mathrm{a}}$, R. Sirera ${ }^{\mathrm{a}}$, J.I. Alvarez ${ }^{\mathrm{a}^{*}}$

${ }^{a}$ MIMED Research Group; Department of Chemistry and Soil Sciences, School of Sciences, University of Navarra. Irunlarrea, 1. 31008 Pamplona, Spain

\begin{abstract}
Polynaphtalenesulfonate (PNS) and lignosulfonate (LS) were tested as superplasticizers in pastes and mortars of pure air lime and air lime with a pozzolanic additive, nanosilica (NS). LS showed a better plasticizing effect than PNS: the flowability of the samples with LS as well as the slump retention over time was larger. LS strongly hindered carbonation due to its ability to form $\mathrm{Ca}^{2+}$ complexes. In mortars with NS, PNS was seen to interfere with the C-S-H formation, resulting in lower mechanical strengths. Adsorption isotherms and zeta potential showed that PNS was more adsorbed than LS onto lime and C-S-H particles. PNS acted mainly through electrostatic repulsion owing to its high anionic charge density and flat adsorption. However, LS was more efficient as superplasticizer in air lime media, steric hindrance being the main mechanism responsible for avoiding flocculation. Furthermore, LS yielded high compressive strengths in mortars with NS.
\end{abstract}




\section{Introduction}

Polynaphtalenesulfonate (PNS) and lignosulfonate (LS) are two widely used superplasticizers (SP) in the field of binding materials for building purposes. The PNS is a polymeric molecule formed by condensation of naphthalene sulfonic acid and formaldehyde, in which the hydrophilic groups are mainly sulfonic groups, whereas the hydrophobic part is naphthalene. The chemical structure of LS contains hydrophilic parts (such as sulfonic, methoxyl and hydroxyl groups) as well as a hydrophobic carbon chain (alkylbenzene) [1,2]. The presence of sulfonate groups is responsible for the negatively charged molecules in both superplasticizers at the alkaline $\mathrm{pH}$ of the cement media. Therefore, the SP units can be attached to positively charged particles of the binding material, provoking electrosteric repulsions that hinder the agglomeration of the fresh mixture, thereby increasing its fluidity. PNS has been reported to be a high-range water reducer (water demand reduction up to $20 \%$ ), while LS has been classified as a standard water reducer (water demand drop $<12 \%$ ) [1].

With respect to the molecular weight, the fluidity of cement mortars samples containing high molecular weight PNS has been found to be larger than that with low molecular weight PNS, in connection with (i) a better adsorption onto cement particles that increased the steric hindrance, and (ii) a larger electrostatic repulsion owing to the higher number of anionic groups [3].

PNS is generally better adsorbed than LS onto cement particles and the later has shown a clear trend to $\mathrm{Ca}^{2+}$ complexation, causing a strong delay in the setting time $[2,4]$. On the use of PNS, it has been reported that the formation of organo-mineral compounds by the intercalation of superplasticizer molecules within the hydration products (mainly C$\mathrm{S}-\mathrm{H}$ phases) occurs, leading to an intense consumption of the SP in the early hydration stages [5-7]. 
While many works dealt with the effect of PNS and LS in cement systems [8-11], there is a gap in the scientific literature on the performance of these two superplasticizers when added to either air lime mortars or air lime mortars modified upon the presence of nanosilica, a pozzolanic additive to obtain hydraulic lime mortars. Therefore, the aim of the present work is to ascertain the behaviour of air lime pastes and mortars including PNS or LS as superplasticizer admixtures. Furthermore, the role of these SPs in air lime mixtures with nanosilica will be also tested. These systems have shown a wide range of applications (such as consolidant products and repair materials for restoration of the Built Heritage) in which the use of compatible and effective superplasticizers is necessary [12-18]. About the effect of superplasticizers on lime mortars, literature shows a limited number of works dealing with it. A reduction in the water demand was reported for mortars treated with sulfonated melamine and different improvements, especially in mechanical strengths, were seen in samples treated with polycarboxylatebased plasticizers $[13,17,19-20]$. In pure air lime mortars as compared with cement mortars, the absence of C-S-H phases, the high $\mathrm{Ca}^{2+}$ concentration and the large water demand in the fresh state are factors that should be considered since they can have a strong influence on the performance and required dosages of the superplasticizers.

\section{Materials and methods}

\subsection{Materials}

A powdered slaked lime (CALINSA, Spain) of the CL 90-S class, according to the European standard [21] was used for preparing pastes and mortars. A pozzolan, namely nanosilica, was used in some cases to obtain hydraulic mortars. Nanosilica (NS, ULMEN Europa S.L.) is a colloidal, superplasticizer-free silica suspension, solid/liquid 
ratio of 0.28 and $\mathrm{pH}=9.68$. Its specific surface area was ca. $500 \mathrm{~m}^{2} \mathrm{~g}^{-1}$ and the average particle size was around $50 \mathrm{~nm}[17]$.

Different weight percentages $(0,6,10$ and $20 \mathrm{wt} . \%$ with respect to the weight of lime) of NS were added to obtain pastes in which the flowability and other properties were assessed.

Two different commercially available superplasticizers (SPs), polynaphtalenesulfonate (PNS) and lignosulfonate (LS), were added in several percentages with respect to the weight of lime: $0.25,0.50,0.75$ and $1.00 \%$. FTIR characterization of both admixtures was carried out and their spectra are shown in Fig. 1. For PNS, its spectrum shows that the polymer molecule contains the aromatic C-H stretching band at ca. $3060 \mathrm{~cm}^{-1}$ and aromatic rings modes at $1624 \mathrm{~cm}^{-1}$ and $1595 \mathrm{~cm}^{-1}[22,23]$. Bands at 1177 and $1030 \mathrm{~cm}^{-1}$ were assigned to sulfonate groups. The other signals correspond to $\mathrm{S}=\mathrm{O}$ stretching vibration at $1355 \mathrm{~cm}^{-1}$ and S-O group at $677 \mathrm{~cm}^{-1}$ [22]. With respect to LS admixture, the broad band at $3600-3300 \mathrm{~cm}^{-1}$ (centered at ca. $3400 \mathrm{~cm}^{-1}$ ) was assigned to $-\mathrm{OH}$ stretching vibrations corresponding to phenolic and carboxylic acids [24-26]. The sharp bands at ca. 1180 and $1040 \mathrm{~cm}^{-1}$ are the characteristic vibrations of the sulfonic groups [25], and also the band at $620-660 \mathrm{~cm}^{-1}$ [27].

By size-exclusion chromatography (SEC) the following molecular weight were obtained: for PNS, 8620 Da, and for LS 8650 Da. Elemental analyses carried out with a LECO analyzer revealed that both SPs have similar percentages of C (around 50\%) and the sharpest difference was found for S contents: PNS had $12.3 \%$, LS only had a $6.2 \%$. The determination of the anionic charge density of the SPs was performed by titration using a positively charged polymer, Poly-DADMAC [28]. Results showed 2.44 meq of anionic charge/g of polymer for PNS and $1.04 \mathrm{meq}$ of anionic charge/g of polymer for 
LS. Considering that sulfonate groups are the main group responsible for the anionic charge, these results shows a good correlation with the elemental analysis results.

\subsection{Methods}

\subsubsection{Pastes and mortars preparation}

For the preparation of the pastes, lime and the required amount of dry SPs were blended for 5 min using a solid admixtures mixer BL-8-CA (Lleal, S.A., Spain). To obtain mortars, a calcitic sand (limestone aggregate) was used in a binder/aggregate ratio 1:1 by volume (1:3 by weight). Water and the pozzolanic material (NS) were then added and mixed for $90 \mathrm{~s}$ at low speed, in a Proeti ETI 26.0072 mixer.

As the tested admixtures were strong modifiers of the fluidity of the pastes and mortars, it was decided to maintain as a fixed ratio for all samples the water/lime ratio. To this aim, the water/lime ratio that provided a suitable workability in the control sample was chosen (slump in the flow table test within the range of $175 \pm 5 \mathrm{~mm}$ ).

Mortar samples were moulded in prismatic 40x40x160 mm, stored at $20{ }^{\circ} \mathrm{C}$ and $60 \%$ RH and demoulded 7 days later. Different curing times were considered: 7, 28, 91 and 182 days. In order to make the results representative, mortars were tested at each curing time in triplicate.

\subsubsection{Experimental measurements}

The mini-spread flow test was applied to establish the consistency of the pastes [29] at $0,30,60,90,120$ and 150 min after the pastes preparation in order to know the slump loss (also called dispersion maintaining ability) over the time. Setting time in pastes was determined according to the European test [30]. 
Sorption experiments for PNS and LS were carried out in batch reactors in which individual and multicomponent suspensions (5 $\mathrm{g}$ of lime, NS at 6, 10 and $20 \mathrm{wt}$. \% with respect to lime) in $25 \mathrm{~mL}$ of water were tested. The mixtures were stirred for $1 \mathrm{~h}$ and, subsequently, centrifugated at $8000 \mathrm{~g}$ for $15 \mathrm{~min}$. The supernatant was collected and filtered through $0.45 \mu \mathrm{m}$ PTFE filters. The amount of PNS and LS adsorbed was determined by the difference between the initial and final concentrations of the SPs in the solution, quantified by means of ultraviolet-visible spectrophotometry (maxima at $\lambda=296 \mathrm{~nm}$ for PNS and at $\lambda=285 \mathrm{~nm}$ for LS). Mathematical algorithms were used to estimate the adjustment of the data. The Freundlich model was used to fit the adsorption data.

$\mathrm{q}=\mathrm{K} \cdot \mathrm{C}^{1 / \mathrm{n}}$

In this model q represents the amount of SPs adsorbed onto the solid particles $\left(\mathrm{mg} \cdot \mathrm{g}^{-1}\right)$, $\mathrm{C}$ is the concentration of SPs in solution $\left(\mathrm{mg} \cdot \mathrm{L}^{-1}\right)$, and $\mathrm{K}$ and $1 / \mathrm{n}$ are the Freundlich constants.

The zeta potential of the SPs (PNS or LS) and the lime and/or NS was determined using an electroacoustic-based zeta potential analyser (ZetaProbe of Colloidal Dynamics). Individual and multicomponent suspensions, formed of $7 \mathrm{~g}$ of lime and $82 \mathrm{ml}$ of NS suspension per $140 \mathrm{ml}$ of water, were prepared and allowed to react for $30 \mathrm{~min}$ to ensure the pozzolanic reaction had taken place. $1 \% \mathrm{w} / \mathrm{v}$ SPs solutions were used as titrants when necessary.

To assess the action mechanisms, analyses of the pore solution were carried out for lime dispersions vs. increasing dosages of the SPs. Calcium concentrations were determined after centrifugation. In other lime dispersions, a specific SP amount was added and the evolution of the calcium concentration over time was studied. 
Mortars samples were analysed by X-ray powder diffraction (XRD) in a Bruker D8Advance diffractometer with a $\mathrm{Cu} K \alpha 1$ radiation and step size of $0.04^{\circ}, 1$ s per step, from $2^{\circ}$ to $80^{\circ}(2 \theta)$, and by Fourier Transform Infrared Spectroscopy-Attenuated Total Reflectance (FTIR-ATR) in a Nicolet Avatar 360 apparatus. The infrared spectra were the result of averaging 100 scans over a range of $400-600 \mathrm{~cm}^{-1}$, with resolution of $4 \mathrm{~cm}^{-}$

1. The thermal behaviour of the samples was assessed by using a simultaneous TGsDTA 851 Mettler Toledo device with the following experimental conditions: alumina crucible, temperature range from 25 to $1000{ }^{\circ} \mathrm{C}, 10{ }^{\circ} \mathrm{C} \cdot \mathrm{min}^{-1}$ heating rate, and static air atmosphere. The morphology and microstructure of the samples was examined with a Hitachi S-4800 scanning electron microscope (SEM), coupled to an EDS detector, was employed. In order to arrest the hydration, samples were immersed in liquid $\mathrm{N}_{2}$ for 5 min and straight afterwards subjected to a freeze-drying procedure. Samples were coated with gold films before SEM-EDS studies. Pore size distributions were obtained by means of mercury intrusion porosimetry (MIP), using a Micromeritics AutoPore IV 9500 with a pressure range between 0.0015 and $207 \mathrm{MPa}$. Flexural strengths were determined in the prismatic specimens by the three-point flexural tests at low rates of loading $\left(10 \mathrm{~N} \cdot \mathrm{s}^{-1}\right)$. Compressive strength tests were executed on the two fragments of each specimen resulted from the flexural tests and the rate of loading was $50 \mathrm{~N} \mathrm{~s}^{-1}$.

\section{Results and discussion}

\subsection{Dispersing action and slump retention}

Fig. 2 gives the slump results, which show that, generally speaking, the addition of both superplasticizers increased the flowability of the plain air lime pastes. However, LS was more effective in these pastes than PNS, as evidenced by the largest slump (ca. 195 $\mathrm{mm}$ ) achieved at the lowest dosages tested (0.25\%). While PNS showed a clear dosage- 
response pattern (the higher the PNS dosage, the larger the slump), LS did not present a clear relationship between the flowability and the dosage.

In the presence of the pozzolanic additive, NS, the consistency of the pastes clearly increased (slump reduction) in good agreement with previous results in which the small particle size of the NS increased the water demand [31,32]. The higher the amount of NS, the stronger the slump reduction. In these NS-air lime pastes, the effectiveness as superplasticizer of both admixtures was found to be similar, although the average values pointed to a slightly better performance of the LS as compared with PNS. The influence of the superplasticizer dosages turned out to be unclear for LS: in the case of this admixture, the addition of $0.5 \mathrm{wt} \%$ usually resulted in a slump increase. However, when the highest dosage ( $0.75 \mathrm{wt} . \%)$ was added, even a slump reduction was sometimes measured.

In order to reach a complete assessment of the performance of these superplasticizers in air lime pastes, the slump loss over the time was measured. The knowledge about the dispersion maintaining ability provides relevant information about the usefulness of the different admixtures and about the necessity of delayed additions [33-35].

Fig. 3 shows that LS has a greater slump retention than PNS in plain air lime pastes: at 150 minutes after the paste preparation, blends with LS lost ca. $13 \%$ of their slump value, while samples with PNS underwent a pronounced slump loss of ca. $35 \%$.

In the presence of NS, the slump retention was similar for both admixtures (Fig. 4), yielding around $5 \%$ of slump loss, although in this case the slump values at 0 min were very low $(<135 \mathrm{~mm})$. These low fluidity values with small changes over time for these NS-bearing pastes are comparable to the performance reported for polycarboxylate ethers superplasticizers [13]. 
The setting time evaluation depicted in Fig. 5 showed that, for plain air lime pastes, the presence of both SPs induced a delay. LS caused the strongest delay in the setting time, especially at the largest dosage tested.

In mixtures of air lime with NS (dosages 6 and $10 \mathrm{wt} \%$ of the pozzolanic additive), even the SP-free air lime pastes underwent a severe delay in the setting time. In these pastes, the presence of LS further delayed setting, whereas PNS reduced the setting time in most cases, compared with SP-free pastes.

When considering the parameters affecting the setting time of air lime pastes, it must be taken into account that the hardening process is related to the uptake of $\mathrm{CO}_{2}$ and carbonation of the $\mathrm{Ca}(\mathrm{OH})_{2}$ yielding $\mathrm{CaCO}_{3}$. The incorporation of a pozzolanic additive, such as NS, caused the pozzolanic reaction and the hydration of the products resulting in C-S-H phases [36,37]. A previous work has described the significance of the irreversible agglomeration of the lime particles on the setting, so that any possible interference with this agglomeration would cause a setting time delay [38]. In this work, the assessment of the setting time also was helpful to see that the use of LS is not very recommendable owing to the strong delay in the setting time that this admixture causes: air lime pastes or mortars with LS to be used, for example, as grouts would be virtually non-applicable due to the slowing down of the setting. From the results it can be also inferred that the largest dosage tested was not suitable owing to the severe interference with the hardening process of the pastes.

\subsection{Properties of the hardened mortars}

Flexural strength values are depicted in Fig. 6, from which it can be concluded that, in general, the presence of PNS yielded higher flexural resistances (average value 0.78 $\mathrm{MPa})$ than that measured for mortars with LS (0.67 MPa as average value). For samples 
with $0.5 \mathrm{wt} . \%$ of PNS, the greatest strengths were achieved for NS-free mortars, whereas the presence of PNS when pozzolanic additive was also added turned out to be detrimental for the flexural strength. It must be however taken into account that flexural strength is strongly dependent on the humidity level of the specimen. In connection with the dramatic increase between values after 7 and 28 curing days that was measured for NS-free mortars with PNS, it has to be considered that the presence of PNS increased the amount of free water, being the loss of this residual water responsible for the observed increase in strength at the early stages of hydration. In this sense, it has to be noticed that the presence of NS (which raised the water demand) caused a less marked differences between strengths at 7 and 28 days.

In line with the results reported by Grilo et al. [39], the reduction that was observed after 28 days in samples with increasing amounts of NS could be caused by the shrinkage with microcracking due to the different water availability.

As for the compressive strength (Fig. 7), PNS yielded better results for plain air lime mortars (NS-free samples, 2.38 MPa for PNS- samples vs. 1.18 MPa for LS-samples), while LS was seen to be more effective when also NS was added (average values of 4.3 for LS-samples vs. 3.5 MPa for PNS-bearing samples). Samples with 20\% NS and LS offered the largest values of compressive strength (above $7 \mathrm{MPa}$ after just 28 curing days and even reaching ca. $9 \mathrm{MPa}$ after 182 curing days, sample with 1 wt. \% of lignosulfonate).

The degree of carbonation was helpful to understand these results: the presence of LS clearly hindered the carbonation, as XRD, thermal analysis and FTIR studies showed. XRD phase evolution over time showed that the intensity of the main peak of the uncarbonated portlandite was larger in the presence of LS, while the amount of calcium carbonate (as calcite) was lower in comparison with the samples containing PNS. As an 
example, from the XRD results, Fig. 8 shows the percentages of uncarbonated $\mathrm{Ca}(\mathrm{OH})_{2}$ and $\mathrm{CaCO}_{3}$ in air lime mortars after different curing days. These percentages were calculated by comparison between the intensities of the main diffraction peaks of the crystalline phases $[39,40]$. It can be seen that the presence of LS hindered the carbonation, resulting in higher amounts of $\mathrm{Ca}(\mathrm{OH})_{2}$ and lower amounts of $\mathrm{CaCO}_{3}$. This fact took place in plain air lime samples as well as in NS-air lime samples.

Quantitative values obtained by TG (Table 1) confirmed these results: the presence of LS yielded comparatively higher content in $\mathrm{Ca}(\mathrm{OH})_{2}$ (weight loss due to dehydroxylation of portlandite at ca. $450^{\circ} \mathrm{C}$ ) and lower amounts of $\mathrm{CaCO}_{3}$ (weight loss owing to the calcite decomposition at ca. $800^{\circ} \mathrm{C}$ ) [41]. FTIR spectra in Fig. 9 evidenced, in plain air lime samples with LS after 91 curing days, a sharp and intense absorption band at ca. $3600 \mathrm{~cm}^{-1}$ ascribed to $-\mathrm{OH}$ groups of the portlandite. Samples with PNS showed a very small signal, pointing to a lower content in $\mathrm{Ca}(\mathrm{OH})_{2}$. At the same time, absorption band at $1410 \mathrm{~cm}^{-1}$, related to the carbonate group, appeared much less intense in LS-bearing samples than in samples with PNS or even in plain lime samples [41]. In air lime-NS mortars, FTIR spectra showed similar features (Fig. 10): a strong absorption band related to the calcite presence was observed in PNS-samples. At ca. $3600 \mathrm{~cm}^{-1}$, a sharp signal due to the $-\mathrm{OH}$ groups of the portlandite was seen in LSsamples. In comparison with NS-free samples, the intensity of this band was lower since a significant amount of portlandite reacted with NS during the pozzolanic interaction. Furthermore, the spectrum of this LS-sample also showed an intense band related to the presence of C-S-H (ca. $1000 \mathrm{~cm}^{-1}$ ) [41]. In samples with NS, a quantitative analysis of C-S-H content was carried out by means of TG (Table 2): the weight loss in the range between 25 and $300^{\circ} \mathrm{C}$ was ascribed to the dehydration of C-S-H [42-43]. The obtained values were in line with those reported even for the hydration of pure C3S pastes with 
NS [42]. It can be seen that, after 91 curing days, the presence of LS clearly favoured the C-S-H formation with respect to samples treated with PNS. By XRD, the higher intensity of the peaks at ca. 30 and $50.7^{\circ} 2 \theta$ in LS samples as compared to PNS samples evidenced the larger formation of C-S-H in LS samples (Fig. 11).

All these results prove that LS inhibited carbonation of the air lime mortars whereas improved the C-S-H formation in the presence of a pozzolanic additive. On the other hand, PNS favoured the carbonation of the slaked lime while hindering the C-S-H formation. A discussion on the action mechanisms of these two admixtures that explains these results is presented below in section 3.3.

Microstructural examination carried out in hardened mortars by SEM also agrees with these conclusions. As an example, Fig. $12 \mathrm{a}$ and $\mathrm{b}$ depicts two micrographs of samples with $20 \%$ NS and $1 \%$ of PNS and LS, respectively, after 182 curing days. It can be observed that in PNS samples the volume of carbonated lime is preponderant arising as agglomerations of calcite crystals, with corroded surfaces, similar to previous studies of air lime mortars $[44,45]$. Few C-S-H fibres can also be identified. However, in LS samples, some areas observed by SEM showed that the amount of carbonated lime areas is much lower, and the textural examination in these areas reveals a predominance of C$\mathrm{S}-\mathrm{H}$ compounds as the main hydration products, identified by their thin foil shape (sometimes resembling honeycomb structures) and a large agglomeration of C-S-H fibres (see the detail in Fig. 12c) and confirmed by EDAX analysis [13].

The formation of C-S-H as the main hydration product was a consequence of the pozzolanic reaction: foil-like structure was seen to be present in control mortars, as shown in Fig. 13 in which comparative micrographs of control mortars (with and without NS) are depicted. Upon the addition of both SPs, the predominance in samples 
with NS of the foil-like structures as the main hydration product was also observed, in comparison to samples NS-free (Figs. 14 and 15).

Pore size distribution measurements (see Fig. 16 for some examples) carried out by MIP showed that the addition of the pozzolanic additive reduced the porosity related to pores around $1 \mu \mathrm{m}$ of diameter due to the filler effect of the nanosilica and to the occurrence of the pozzolanic reaction. In addition, small capillary pores ascribed to the formation of $\mathrm{C}-\mathrm{S}-\mathrm{H}$ underwent a clear increase (see pore range between 0.1 and $0.01 \mu \mathrm{m}$ ) [46]. The reduction in larger pores and the formation of C-S-H explains the increase in mechanical strengths as a consequence of the NS presence. However, with respect to CS-H pores, the distinct performance of LS and PNS can be confirmed: PNS, at the two tested dosages, yielded the lowest areas under the curves in the pore range $0.1-0.01$ $\mu \mathrm{m}$ conversely to the highest ones observed for LS, evidencing that the presence of PNS hampered the C-S-H formation.

\subsection{Action mechanism: adsorption and zeta potential assessment}

In the fresh state, the adsorption of both superplasticizers onto pure air lime, NS and a blended system NS-air lime was assessed. Adsorption isotherms showed, according to a Langmuir adjustment, that PNS exhibited a higher affinity than that of the LS for air lime particles (see, in Table $3, \mathrm{q}_{\mathrm{m}}$ values, maximum sorption capacity). Mathematical treatment of experimental data showed a better adjustment to a Freundlich model, in which interactions arising from multilayer adsorption are taken into account (Table 3). Adsorption experiments carried out in pure NS dispersions showed that PNS did not absorb onto NS particles, while LS showed a certain affinity for this substrate (the maximum adsorption capacity was $40 \mathrm{mg}$ of LS in $1000 \mathrm{mg}$ of NS tested with a LS

concentration of $6000 \mathrm{mg}$. $\mathrm{L}^{-1}$, according to Fig. 17). When NS-air lime systems were 
studied, PNS was adsorbed onto solid particles to a larger extent than LS. These findings point to a greater interaction of PNS with air lime media (pure air lime or air lime with pozzolanic additives).

Zeta potential assessment also confirmed these results: the titrations of a dispersion of air lime particles with a solution of the superplasticizers are depicted in Fig. 18 (NS-free air lime media) and in Fig. 19 (air lime + NS media). Several facts can be observed:

i) The dispersions start from positive zeta potential values, in good agreement with previous works $[13,17,47]$. Air lime particles offered positive values of the surface charge around $+20 \mathrm{mV}$, ascribed to the zeta potential of the portlandite particles (Fig. 18). Air lime and nanosilica showed large positive values (ca. $+60 \mathrm{mV}$, Fig. 19): in this case, the pozzolanic reaction is assumed to yield mainly C-S-H phases (negatively charged at alkaline $\mathrm{pH}$ owing to the silanol groups deprotonation) that are strongly sheltered by a layer of $\mathrm{Ca}^{2+}$ counterions, resulting in a positive overcharging phenomenon [48-51].

ii) The progressive incorporation of the superplasticizer molecules caused a shift of the zeta potential towards more negative (less positive) values (Fig. 18 and 19). At the alkaline $\mathrm{pH}$ of both media, sulfonate groups of PNS and LS are expected to be deprotonated, conferring a negative charge to the polymers. Some polymer molecules would be attached to the positive layer of the portlandite and C-S-H, explaining the zeta potential evolution. Changes in the zeta potential depend on the negative charge density of the polymeric molecules, on the amount of the adsorbed admixture and on the molecular architecture of the polymer that influences the type of adsorption (flat or perpendicular) and the subsequent displacement of the shear plane of the outer Helmholtz layer [17]. 
In pure air lime media upon progressive addition of the polymers, the zeta potential measurements consistently depicted an unexpected serrated pattern (Fig. 18). A first stage showed a continuous decrease of the surface charge owing to the monolayer adsorption of the negatively charged molecules of the superplasticizers. Secondly, a pronounced increase towards more positive values was seen, after which again a continuous decrease was measured. The formation of a second adsorption layer of calcium ions, described as potential determining ions [49-52], on the top of the first SP monolayer could account for the sharp increase in zeta potential. The subsequent adsorption of a second layer of superplasticizers would explain the later decrease in the zeta potential. The formation of these two layers of SPs matches well the aforementioned multilayer Freundlich model adsorption isotherms.

In cement media, literature has reported bilayer adsorption model for some superplasticizers, although this fact has not been experimentally supported by zeta potential measurements [9]. In the current work, the air lime system provides a very high concentration of $\mathrm{Ca}^{2+}$ ions, which would explain the strong interaction responsible for the second $\mathrm{Ca}^{2+}$ layer. The high cation concentration increased the ionic strength around lime particles, provoking a certain contraction of the double layer that explains its detection by zeta potential measurements [53]. This kind of strong zeta potential oscillation has been reported for polyelectrolyte multilayer systems [54-57] and also for bilayer adsorptions [58].

iii) PNS and LS present some quantitative differences. In pure air lime system, for LS, the increase in zeta potential after the first SP adsorption layer was more intense than that for PNS (Fig. 18). This fact might be correlated with the high affinity of LS for $\mathrm{Ca}^{2+}$ complexation $[2,4]$. At the same time, the curve for PNS showed a larger zeta potential reduction (even giving rise to a charge reversal) as a consequence of the higher 
anionic charge density of this polymer ( $2.44 \mathrm{meq}$ of anionic charge/g of polymer for PNS in the face of 1.04 meq of anionic charge/g of polymer for LS) (Fig. 18). Also in air lime + NS systems PNS caused a stronger reduction of the zeta potential than that of the LS (Fig. 19). This fact is in accordance with the larger amount of adsorbed PNS (Table 3) and with the higher anionic charge density of this polymer.

The dispersion effectiveness discussed in section 3.1 showed that LS was more effective in air lime and in air lime + NS pastes. In spite of its lower adsorption and interaction in terms of surface charge as compared to PNS, LS yielded higher slump values and presented a lower slump loss over the time. In this sense, LS has been reported to easily form $\mathrm{Ca}^{2+}$ complexes [2,4], avoiding some molecules to be attached to the portlandite or CSH particles. These "free" LS molecules in the interstitial solution may act as a steric hindrance to prevent particles from agglomeration, explaining the better plasticizing action of this admixture [7]. At the same time, the $\mathrm{Ca}^{2+}$ chelation would explain the strong interference of this polymer with the carbonation process discussed in section 3.2, since the latter needs a supersaturated solution of $\mathrm{Ca}^{2+}$ ions, whose concentration was reduced by the polymer presence. The strong delay in setting time caused by this LS admixture in pure air lime mortars is a clear consequence of this low carbonation rate, since carbonation is the main process governing the setting of air lime mortars.

The ability of $\mathrm{LS}$ to form $\mathrm{Ca}^{2+}$ complexes was confirmed by $\mathrm{Ca}^{2+}$ complexation studies in the studies of the pore solution. It can be seen in Fig. 20 that, in lime dispersions (with or without NS) the presence of "free" $\mathrm{Ca}^{2+}$ ions in the suspension was always lower in the presence of LS as compared to PNS. The larger the amount of SP, the lower the free $\mathrm{Ca}^{2+}$ content. The effect of the presence of $\mathrm{NS}$ on the $\mathrm{Ca}^{2+}$ content was also individually studied (Fig. 21). The NS incorporation caused changes in the $\mathrm{Ca}^{2+}$ content of the same order of magnitude than those due to the presence of the 
superplasticizer. These results were confirmed even for a $30 \mathrm{wt} . \%$ of NS incorporation. Finally, from the studies of the $\mathrm{Ca}^{2+}$ content over the time (Fig. 22), it can be concluded, for example, that in samples with NS the presence of LS initially caused a sharp drop in the calcium concentration, confirming the strong interaction of this admixture with the calcium ions at the very early stages of the reaction.

The formation of these $\mathrm{Ca}^{2+}$ complexes with LS also allowed to explain the absence of a clear dosage-response pattern in the case of this admixture: large dosages of LS can lead to a cross-linking phenomenon between polymer chains and lime particles, thus causing a flowability reduction in the paste. Fig. 2 shows several examples of slump reduction for high LS dosages.

In addition, the molecular architecture of both polymers also influences their distinct performance: for PNS, a flat adsorption has been proposed owing to its higher anionic charge density and to its linear shape [59-61], whereas LS adsorption would be more "perpendicular" to the surface of the particles (since its molecular architecture was treeshaped, randomly branched polyelectrolyte) [10,24], giving rise to different fragments of molecular chains arising from the surface of the particles. In the case of PNS and owing to its flat adsorption, the attached molecules could be surrounded by the growing carbonation/hydration products, yielding organo-mineral phases [5-7]. This fact renders the attached molecules inactive, thus explaining the experimental results showing a lower dispersion effectiveness of this admixture and its really poor dispersion maintaining ability. These findings also point to the electrostatic repulsion as the main action mechanism to explain the PNS action, whereas the steric hindrance would be the main mechanism for LS. In good agreement with previous results on the effect of polycarboxylate ether superplasticizers, for air lime media, the superplasticizer with a 
predominant mechanism based on steric hindrance was seen to be less adsorbed and more effective than the superplasticizer with a mechanism of electrostatic repulsion.

In spite of the better plasticizing action of LS, it has to be taken into account that, in pure air lime pastes and mortars, the use of LS should be carefully considered, given that it causes a strong delay in setting time and hinders the carbonation jeopardising the mechanical strength.

Conversely, in air lime media modified upon the addition of a pozzolanic additive, NS, LS would be a better superplasticizer than PNS, since in the presence of LS the formation of C-S-H is favoured. PNS, on the contrary, gave rise to a lower content of C$\mathrm{S}-\mathrm{H}$ yielding lower resistances. As a hypothesis, the formation of inactive organomineral phases, like in cement systems, could explain this effect. Zeta potential evolution in air lime + NS pastes (Fig. 19) and adsorption isotherms (Table 3) showed that PNS interacted in a stronger way with the nuclei of the C-S-H crystal growth.

\section{Conclusions}

In air lime-based media, the comparative study between polynaphtalenesulfonate and lignosulfonate revealed that LS was more effective in increasing the fluidity of the samples. LS was able to form $\mathrm{Ca}^{2+}$ complexes that yielded "free" LS molecules in the suspension: these molecules were responsible for a strong steric effect that avoided flocculation accounting for the better plasticizing effect of this admixture. At the same time, the $\mathrm{Ca}^{2+}$ complexation prevented lime mortars from carbonation, thus causing a delay in setting time and lower mechanical strengths for pure air lime mortars, so that LS should be used cautiously in this kind of mortars.

Adsorption isotherms showed that more PNS was adsorbed onto the lime and C-S-H particles than LS. Zeta potential also showed that the interaction of PNS modified the 
zeta potential into a greater extent. These facts were a consequence of the high anionic charge density of PNS and its "flat" adsorption mechanism onto particles. PNS gave rise to the formation of organo-mineral phases that increased its consumption showing a poor plasticizing performance and low slump retention capacity.

In mortars with the pozzolanic NS addition, the presence of PNS hindered the C-S-H formation resulting in lower mechanical strengths. Electrostatic repulsion has been ascertained as the main mechanism of PNS. LS favoured the formation of C-S-H with the corresponding improvement in mechanical resistance and should be preferred for this type of mortars. In this case, LS acted mainly through a steric hindrance mechanism.

\section{Acknowledgements}

The authors want to thank CTH Navarra, ULMEN, Lapiberia and Calinsa S.A. Navarra for the material supplied. Assistance of Dr. González Gaitano in SEC analysis is greatly acknowledged. This work was funded by Fundación Universitaria de Navarra under grant FUNA2013-15108402 and Fundación Caja Navarra under grant 31-2014. M. Pérez-Nicolás thanks the Friends of the University of Navarra, Inc., for a pre-doctoral grant.

\section{References}

[1] Ouyang,X.; Qiu,X.; Chen, P. Physicochemical characterization of calcium lignosulfonate-A potentially useful water reducer. Colloids Surf., A 2006, 282-283, 489-497; DOI: 10.1016/j.colsurfa.2005.12.020 
[2] Uchikawa, H.; Hanehara, S.; Shirasaka, T.; Sawaki, D. Effect of admixture on hydration of cement, adsorptive behavior of admixture and fluidity and setting of fresh cement paste. Cem. Concr. Res. 1992, 22(6), 1115-1129; DOI: 10.1016/00088846(92)90041-S

[3] Collepardi, M.; Corradi, M.; Valente, M. Influence of polymerization of sulfonated naphthalene condensate and its interaction with cement, In 2nd International Conference on Superplasticizer and Other Chemical Admixtures in Concrete, Malhotra, V.M., Ed.; Ottawa, Canada, 1981; pp. 485

[4] Vikan, H.; Justnes, H.; Figi, R. Adsorption of plasticizers - Influence of plasticizer and cement type. Annual Transactions of the Nordic Rheology Society 2005, 13, 127 134

[5] Alonso, M.M.; Puertas, F. Adsorption of PCE and PNS superplasticisers on cubic and orthorhombic $\mathrm{C}_{3} \mathrm{~A}$. Effect of sulphate. Constr. Build. Mater. 2015, 78(1), 324-332; DOI: $10.1016 /$ j.conbuildmat.2014.12.050

[6] Yahia, A.; Tanimura, M. Rheology of belite-cement - Effect of w/c and high-range water-reducer type. Constr. Build. Mater. 2015, 88, 169-174; DOI: 10.1016/j.conbuildmat.2015.03.029

[7] Kim, B.-G.; Jiang, S.; Jolicoeur, C.; Aïtcin, P.-C. The adsorption behavior of PNS superplasticizer and its relation to fluidity of cement paste. Cem. Concr. Res. 2000, 30(6), 887-893; DOI: 10.1016/S0008-8846(00)00256-8

[8] Nakajima, Y.; Yamada, K. The effect of the kind of calcium sulfate in cements on the dispersing ability of poly $\beta$-naphthalene sulfonate condensate superplasticizer. Cem. Concr. Res. 2004, 34(5), 839-844; DOI: 10.1016/j.cemconres.2003.09.022

[9] Zhang, Y.; Kong, X. Correlations of the dispersing capability of NSF and PCE types of superplasticizer and their impacts on cement hydration with the adsorption in fresh cement pastes. Cem. Concr. Res. 2015, 69, 1-9; DOI: 10.1016/j.cemconres.2014.11.009

[10] Danner, T.; Justnes, H.; Geiker, M.; Lauten, R.A. Phase changes during the early hydration of Portland cement with Ca-lignosulfonates. Cem. Concr. Res. 2015, 69, 5060; DOI: 10.1016/j.cemconres.2014.12.004

[11] Milestone, N.B. Hydration of tricalcium silicate in the presence of lignosulfonates, glucose, and sodium gluconate. J. Am. Ceram. Soc. 1979, 62 (7-8);321-324; DOI: $10.1111 /$ j.1151-2916.1979.tb19068.x 
[12] Azeiteiro, L.C.; Velosa, A.; Paiva, H.; Mantas, P.Q.; Ferreira, V.M.; Veiga, R. Development of grouts for consolidation of old renders. Constr. Build. Mater. 2014, 50, 352-360; DOI: 10.1016/j.conbuildmat.2013.09.006

[13] Fernández, J.M.; Duran, A.; Navarro-Blasco, I.; Lanas, J.; Sirera, R.; Alvarez, J.I. Influence of nanosilica and a polycarboxylate ether superplasticizer on the performance of lime mortars. Cem. Concr. Res. 2013, 43, 12-24; DOI: 10.1016/j.cemconres.2012.10.007

[14] Fortes-Revilla, C.; Martinez-Ramirez, S.; Blanco-Varela, M.T. Modelling of slaked lime-metakaolin mortar engineering characteristics in terms of process variables. Cem. Concr. Compos. 2006, 28, 458-467; DOI:10.1016/j.cemconcomp.2005.12.006

[15] Bras, A.; Henriques, F.M.A. Natural hydraulic lime based grouts - The selection of grout injection parameters for masonry consolidation. Constr. Build. Mater. 2012, 26, 135-144; DOI: 10.1016/j.conbuildmat.2011.05.012

[16] Bras, A.; Henriques, F.M.A.; Cidade, M.T. Effect of environmental temperature and fly ash addition in hydraulic lime grout behaviour. Constr. Build. Mater. 2010, 24(8), 1511-1517; DOI: 10.1016/j.conbuildmat.2010.02.001

[17] Navarro-Blasco, I.; Pérez-Nicolás, M.; Fernández, J.M.; Duran, A.; Sirera, R.; Alvarez, J.I. Assessment of the interaction of polycarboxylate superplasticizers in hydrated lime pastes modified with nanosilica or metakaolin as pozzolanic reactives. Constr. Build. Mater. 2014, 73, 1-12; DOI: 10.1016/j.conbuildmat.2014.09.052

[18] Loganina, V.I.; Simonov, E.E.; Jezierski, W.; Małaszkiewicz, D. Application of activated diatomite for dry lime mixes. Constr. Build. Mater. 2014, 65, 29-37; DOI: 10.1016/j.conbuildmat.2014.04.098

[19] Seabra, M.P.; Paiva, H; Labrincha, J.A.; Ferreira V.M.. Admixtures effect on fresh state properties of aerial lime based mortars. Constr. Build. Mater. 2009, 23 1147-1153

[20] Arizzi, A.; Cultrone G. Aerial lime-based mortars blended with a pozzolanic additive and different admixtures: a mineralogical, textural and physical-mechanical study. Constr. Build. Mater. 2012, 31, 135-143

[21] European Committee for Standardization UNE-EN 459-1:2011 Building lime. Part 1: Definition, specification and conformity criteria; CEN: Brussels. 2011. 
[22] El-Didamony, H.; Heikal, M.; Aiad, I.; Al-Marsy, S. Behavior of delayed addition time of SNF superplasticizer on microsilica-sulphate resisting cements. CeramicsSilikáty 2013, 57(3), 232-242.

[23] Ghorab, H.Y.; Kenawi, I.M.; Abdel All, Z.G. Interaction between cements with different composition and superplasticizers. Mater. Construcc. 2012, 62 (307) 359-380; DOI: $10.3989 / \mathrm{mc} .2012 .63610$

[24] Recalde Lummer, N.; Plank, J. Combination of lignosulfonate and AMPS $®-c o-$ NNDMA water retention agent-An example for dual synergistic interaction between admixtures in cement. Cem. Concr. Res. 2012, 42(5), 728-735; DOI: 10.1016/j.cemconres.2012.02.009

[25] Wu, Y.; Zhou, J.; Ye, C.; Sun, H.; Zhao, R. Optimized synthesis of lignosulphonate-g-poly(acrylic acid-co-acrylamide) superabsorbent hydrogel based on the Taguchi method. Iran. Polym. J. 2010, 19 (7), 511-520

[26] Boeriu, C.G.; Bravo, D.; Gosselink, R.J.A.; Van Dam, J.E.G. Characterisation of structure-dependent functional properties of lignin with infrared spectroscopy. Ind. Crops Prod. 2004, 20(2), 205-218; DOI: 10.1016/j.indcrop.2004.04.022

[27] Rodriguez-Lucena, P.; Lucena, J.J.; Hernández-Apaolaza, L. Relationship between the structure of Fe-lignosulfonate complexes determined by FTIR spectroscopy and their reduction by the leaf $\mathrm{Fe}$ reductase. Proceedings of the International Plant Nutrition Colloquium XVI, UC Davis, University of California. 2009; Permalink: https://escholarship.org/uc/item/9k69q71d

[28] Ueno, K.; Kina, K. Colloid titration-A rapid method for the determination of charged colloid. J. Chem. Educ. 1985, 62 (7), 627; DOI: 10.1021/ed062p627

[29] European Committee for Standardization UNE-EN 1015-3:2000 Methods of test for mortar for masonry. Part 3: Determination of consistence of fresh mortar (by flow table); CEN: Brussels. 2000

[30] European Committee for Standarization UNE-EN 1015-9:2000 Methods of test for mortar for masonry. Part 9: Determination of workable life and correction time of fresh mortar; CEN: Brussels. 2000

[31] Ghafari, E.; Costa, H.; Júlio, E.; Portugal, A.; Durães, L. The effect of nanosilica addition on flowability, strength and transport properties of ultra high performance concrete, Mater. Des. 2014, 59, 1-9;DOI: 10.1016/j.matdes.2014.02.051 
[32] Abd.El.Aleem, S.; Heikal, M.; Morsi, W.M. Hydration characteristic, thermal expansion and microstructure of cement containing nano-silica. Constr. Build. Mater. 2014, 59, 151-160; DOI: 10.1016/j.conbuildmat.2014.02.039

[33] Li, Y.; Yang, C.; Zhang, Y.; Zheng, J.; Guo, H.; Lu, M. Study on dispersion, adsorption and flow retaining behaviors of cement mortars with TPEG-type polyether kind polycarboxylate superplasticizers. Constr. Build. Mater. 2014, 64, 324-332; DOI: 10.1016/j.conbuildmat.2014.04.050

[34] Yang, S.; Yue, X.; Liu, X.; Tong, Y. Properties of self-compacting lightweight concrete containing recycled plastic particles. Constr. Build. Mater. 2015, 84, 444-453; DOI: $10.1016 /$ j.conbuildmat.2015.03.038

[35] Ma, S.; Li, W.; Zhang, S.; Ge, D.; Yu, J.; Shen, X. Influence of sodium gluconate on the performance and hydration of Portland cement. Constr. Build. Mater. 2015, 91, 138-144; DOI: 10.1016/j.conbuildmat.2015.05.068

[36] Sáez del Bosque, I.F.; Martínez-Ramírez, S.; Blanco-Varela, M.T. FTIR study of the effect of temperature and nanosilica on the nanostructure of $\mathrm{C}-\mathrm{S}-\mathrm{H}$ gel formed by hydrating tricalcium silicate. Constr Build Mater. 2014, 52, 314-323

[37] Duran A.; Navarro-Blasco I.; Fernández JM.; Alvarez JI. Long-term mechanical resistance and durability of air lime mortars with large additions of nanosilica. Constr Build Mater. 2014, 58, 147-158.

[38] Rodríguez-Navarro, C.; Ruiz-Agudo, E.; Ortega-Huertas, M.; Hansen, E. Nanostructured and irreversible colloidal behaviour of $\mathrm{Ca}(\mathrm{OH})_{2}$ : implications in cultural heritage conservation. Langmuir 2005, 21(24), 10948-10957; DOI: 10.1021/la051338f

[39] Grilo, J.; Santos Silva, A.; Faria, P.; Gameiro, A.; Veiga, R.; Velosa, A. Mechanical and mineralogical properties of natural hydraulic lime-metakaolin mortars in different curing conditions, Constr Build Mater. 2014, 51, 287-294

[40] Fang, S.; Zhang, K.; Zhang, H.; Zhang, B. A study of traditional blood lime mortar for restoration of ancient buildings. Cem. Concr. Res. 2015, 76, 232-241

[41] Lanas, J.; Sirera, R.; Alvarez, J.I. Compositional changes in lime-based mortars exposed to different environments. Thermochim. Acta 2005, 429(2), 219-226;DOI: 10.1016/j.tca.2005.03.015 
[42] Singh, L.P.; Bhattacharyya, S.K.; Shah, S.P.; Mishra, G.; Ahalawat, S.; Sharma, U. Studies on early stage hydration of tricalcium silicate incorporating silica nanoparticles: Part I. Constr Build Mater. 2015, 74, 278-286

[43] Gameiro, A.; Santos Silva, A.; Faria, P.; Grilo, J.; Branco, T.; Veiga, R.; Velosa, A. Physical and chemical assessment of lime-metakaolin mortars: Influence of binder:aggregate ratio. Cem. Concr. Compos. 2014, 45, 264-271.

[44] Mo, L.; Panesar, D.K. Effects of accelerated carbonation on the microstructure of Portland cement pastes containing reactive MgO. Cem. Concr. Res. 2012, 42(6), 769777; DOI: 10.1016/j.cemconres.2012.02.017

[45] Cizer, Ö.; Rodriguez-Navarro, C.; Ruiz-Agudo, E.; Elsen, J.; Van Gemert, D.; Van Balen, K. Phase and morphology evolution of calcium carbonate precipitated by carbonation of hydrated lime. J. Mater. Sci. 2012, 47(16), 6151-6165; DOI: $10.1007 / \mathrm{s} 10853-012-6535-7$

[46] Drouet, E.; Poyet, S.; Torrenti, J.-M. Temperature influence on water transport in hardened cement pastes. Cem. Concr. Res. 2015, 76, 37-50; DOI: 10.1016/j.cemconres.2015.05.002

[47] Pointeau, I.; Reiller, P.; Macé, N.; Landesman, C.; Coreau, N. Measurement and modeling of the surface potential evolution of hydrated cement pastes as a function of degradation. J. Colloid Interface Sci. 2006, 300(1), 33-44; DOI: 10.1016/j.jcis.2006.03.018

[48] Zingg, A.; Winnefeld, F.; Holzer, L.; Pakusch, J.; Becker, S.; Gauckler, L. Adsorption of polyelectrolytes and its influence on the rheology, zeta potential, and microstructure of various cement and hydrate phases. J. Colloid Interface Sci. 2008, 323(2), 301-312; DOI: 10.1016/j.jcis.2008.04.052

[49] Labbez, C.; Pochard, I.; Jönsson, B.; Nonat, A. C-S-H/solution interface: Experimental and Monte Carlo studies. Cem. Concr. Res. 2011, 41(2), 161-168; DOI: 10.1016/j.cemconres.2010.10.002

[50] Jönsson, B.; Nonat, A.; Labbez, C.; Cabane, B.; Wennerstrom, H. Controlling the cohesion of cement paste. Langmuir 2005, 21(20), 9211-9221; DOI: $10.1021 / 1 \mathrm{a} 051048 \mathrm{z}$

[51] Labbez, C.; Nonat, A.; Pochard, I.; Jönsson, B. Experimental and theoretical evidence of overcharging of calcium silicate hydrate. J. Colloid Interface Sci. 2007, 309(2), 303-307; DOI: 10.1016/j.jcis.2007.02.048 
[52] Sowoidnich, T.; Rachowski, T.; Rößler, C.; Völkel, A.; Ludwig, H.-M. Calcium complexation and cluster formation as principal modes of action of polymers used as superplasticizer in cement systems. Cem. Concr. Res. 2015, 73, 42-50; DOI: 10.1016/j.cemconres.2015.01.016

[53] Li, Z.-Y.; Li, J.-Y.; Xu, R.-K.; Hong, Z.-N.; Liu, Z.-D. Streaming potential method for characterizing the overlapping of diffuse layers of the electrical double layers between oppositely charged particles. Colloids Surf., A 2015, 478, 22-29; DOI: 10.1016/j.colsurfa.2015.03.024

[54] Ilyas, S.; de Grooth, J.; Nijmeijer, K.; de Vos, W.M. Multifunctional polyelectrolyte multilayers as nanofiltration membranes and as sacrificial layers for easy membrane cleaning. J. Colloid Interface Sci. 2015, 446, 386-393; DOI: 10.1016/j.jcis.2014.12.019

[55] Hu, L.; Sun, H.; Zhao, Q.; Han, N.; Bai, L.; Wang, Y.; Jiang, T.; Wang, S. Multilayer encapsulated mesoporous silica nanospheres as an oral sustained drug delivery system for the poorly water-soluble drug felodipine. Mater. Sci. Eng., C 2015, 47, 313-324; DOI: 10.1016/j.msec.2014.10.067

[56] Ringwald, C.; Ball, V. Shear induced changes in the streaming potential of polyelectrolyte multilayer films. Colloids Surf., A 2015, 464, 41-45; DOI: 10.1016/j.colsurfa.2014.10.006

[57] Guo, H.; Sun, P.; Liang, Y.; Ma, Y.; Qin, Z.; Cui, S. In-situ fabrication of polyelectrolyte-CSH superhydrophilic coatings via layer-by-layer assembly. Chem. Eng. J. 2014, 253, 198-206; DOI: 10.1016/j.cej.2014.05.025

[58] Oćwieja, M.; Adamczyk, Z.; Morga, M. Adsorption of tannic acid on polyelectrolyte monolayers determined in situ by streaming potential measurements. $J$. Colloid Interface Sci. 2015, 438, 249-258; DOI: 10.1016/j.jcis.2014.09.071

[59] Li, Y.; Zhang, Y.; Zheng, J.; Guo, H.; Yang, C.; Li, Z.; Lu, M. Dispersion and rheological properties of concentrated kaolin suspensions with polycarboxylate copolymers bearing comb-like side chains. J. Eur. Ceram. Soc. 2014, 34(1),137-146; DOI: 10.1016/j.jeurceramsoc.2013.07.009

[60] Li, Y.; Zhu, H.; Yang, C.; Zhang, Y.; Xu, J.; Lu, M. Synthesis and super retarding performance in cement production of diethanolamine modified lignin surfactant. Constr. Build. Mater. 2014, 52, 116-121; DOI: 10.1016/j.conbuildmat.2013.09.024 
[61] Pickelmann, J.; Plank, J. A mechanistic study explaining the synergistic viscosity increase obtained from polyethylene oxide (PEO) and $\beta$-naphthalene sulfonate (BNS) in shotcrete. Cem. Concr. Res. 2012, 42(11), 1409-1416; DOI: 10.1016/j.cemconres.2012.08.003

Table 1. Percentages of $\mathrm{Ca}(\mathrm{OH})_{2}$ and $\mathrm{CaCO}_{3}$ calculated from $\mathrm{TG}$ weight losses for different mortar samples after 7 and 91 curing days.

\begin{tabular}{ccccc}
\hline Sample & $\begin{array}{c}\mathrm{Ca}(\mathrm{OH})_{2} \\
7 \text { days }\end{array}$ & $\begin{array}{c}\mathrm{CaCO}_{3} \\
\mathbf{7 ~ d a y s}\end{array}$ & $\begin{array}{c}\mathrm{Ca}(\mathrm{OH})_{2} \\
\mathbf{9 1} \text { days }\end{array}$ & $\begin{array}{c}\mathrm{CaCO}_{3} \\
\mathbf{9 1} \text { days }\end{array}$ \\
\hline 0\%NS & 12.30 & 82.20 & 2.96 & 93.14 \\
20\%NS & 4.40 & 80.30 & 1.10 & 87.36 \\
0\%NS - 0.50\%PNS & 9.58 & 84.89 & 4.07 & 92.25 \\
20\%NS - 0.50\%PNS & 3.11 & 82.84 & 1.39 & 86.02 \\
0\%NS - 1.0\%PNS & 8.72 & 86.94 & 4.39 & 91.82 \\
20\%NS - 1.0\%PNS & 12.73 & 73.58 & 7.21 & 80.13 \\
0\%NS - 0.50\%LS & 19.76 & 70.82 & 11.02 & 84.95 \\
20\%NS - 0.50\%LS & 9.88 & 76.19 & 5.90 & 79.70 \\
0\%NS - 1.0\%LS & 13.21 & 80.80 & 17.69 & 75.45 \\
20\%NS - 1.0\%LS & 10.40 & 72.91 & 7.25 & 77.11 \\
\hline
\end{tabular}

Relative standard deviation of values was below $0.01 \%$

Table 2. Quantitative percentages of weight losses from TG values in the range 25$300^{\circ} \mathrm{C}$, ascribed to dehydration of C-S-H compounds for different samples after 91 curing days

\begin{tabular}{cc}
\hline Sample & Weight loss \\
\hline $20 \% N S$ & 1.07 \\
$20 \% N S-0.50 \% P N S$ & 1.22 \\
$20 \% N S-1.0 \% P N S$ & 1.20 \\
$20 \% N S-0.50 \% L S$ & 1.77 \\
$20 \% N S-1.0 \% L S$ & 2.07 \\
\hline
\end{tabular}

Relative standard deviation of values was below $0.01 \%$ 
Table 3. Results of adsorption isotherms onto air lime suspensions at different NS percentages: Langmuir and Freundlich adsorption parameters for both SPs.

\section{Polynaphtalenesulfonate}

\begin{tabular}{lcccccc}
\hline & \multicolumn{3}{c}{ Langmuir model } & \multicolumn{3}{c}{ Freundlich model } \\
& $\begin{array}{c}\boldsymbol{q}_{\boldsymbol{m}} \\
\left(\mathrm{mg} \mathrm{g}^{-1}\right)\end{array}$ & $\begin{array}{c}\boldsymbol{b} \\
\left(\mathrm{dm}^{3} \mathrm{mg}^{-1}\right)\end{array}$ & $\boldsymbol{R}^{2}$ & $\begin{array}{c}\boldsymbol{K} \\
\left(\mathrm{mg}^{1-1 / n} \mathrm{dm}^{3 / n} \mathrm{~g}^{-1}\right)\end{array}$ & $\mathbf{1 / n}$ & $\boldsymbol{R}^{2}$ \\
\hline $\mathbf{0 \% N S}$ & 52.08 & $1.07 \cdot 10^{-4}$ & 0.831 & $1.29 \cdot 10^{-2}$ & 0.859 & 0.998 \\
$\mathbf{6 \% N S}$ & 285.71 & $1.77 \cdot 10^{-5}$ & 0.966 & $1.01 \cdot 10^{-2}$ & 0.898 & 0.987 \\
$\mathbf{1 0 \% N S}$ & 3174.60 & $1.51 \cdot 10^{-6}$ & 0.878 & $6.6 \cdot 10^{-3}$ & 0.954 & 0.998 \\
$\mathbf{2 0 \% N S}$ & 3311.26 & $1.44 \cdot 10^{-6}$ & 0.450 & $4.9 \cdot 10^{-3}$ & 0.996 & 1.000 \\
\hline
\end{tabular}

Lignosulfonate

\begin{tabular}{lcccccc}
\hline & \multicolumn{3}{c}{ Langmuir model } & \multicolumn{3}{c}{ Freundlich model } \\
& $\begin{array}{c}\boldsymbol{q}_{\boldsymbol{m}} \\
\left(\mathrm{mg} \mathrm{g}^{-1}\right)\end{array}$ & $\begin{array}{c}\boldsymbol{b} \\
\left(\mathrm{dm}^{3} \mathrm{mg}^{-1}\right)\end{array}$ & $\boldsymbol{R}^{2}$ & $\begin{array}{c}\boldsymbol{K} \\
\left(\mathrm{mg}^{1-1 / n} \mathrm{dm}^{3 / n} g^{-1}\right)\end{array}$ & $\mathbf{1 / n}$ & $\boldsymbol{R}^{2}$ \\
\hline $\mathbf{0 \% N S}$ & 22.94 & $2.72 \cdot 10^{-4}$ & 0.937 & $3.61 \cdot 10^{-2}$ & 0.703 & 0.955 \\
$\mathbf{6 \%} \boldsymbol{N S}$ & 88.50 & $5.12 \cdot 10^{-5}$ & 0.982 & $8.32 \cdot 10^{-3}$ & 0.904 & 0.998 \\
$\mathbf{1 0 \%} \boldsymbol{N S}$ & 151.52 & $2.92 \cdot 10^{-5}$ & 0.987 & $6.46 \cdot 10^{-3}$ & 0.941 & 0.999 \\
$\mathbf{2 0 \%} \boldsymbol{N S}$ & 303.03 & $1.46 \cdot 10^{-5}$ & 0.958 & $5.44 \cdot 10^{-3}$ & 0.968 & 1.000 \\
\hline
\end{tabular}

$\mathrm{q}_{\mathrm{m}}$ : maximum sorption capacity

b: the Langmuir constant

K, $1 / \mathrm{n}$ : the Freundlich constants

$\mathrm{R}^{2}$ : correlation coefficient of the linear regression 


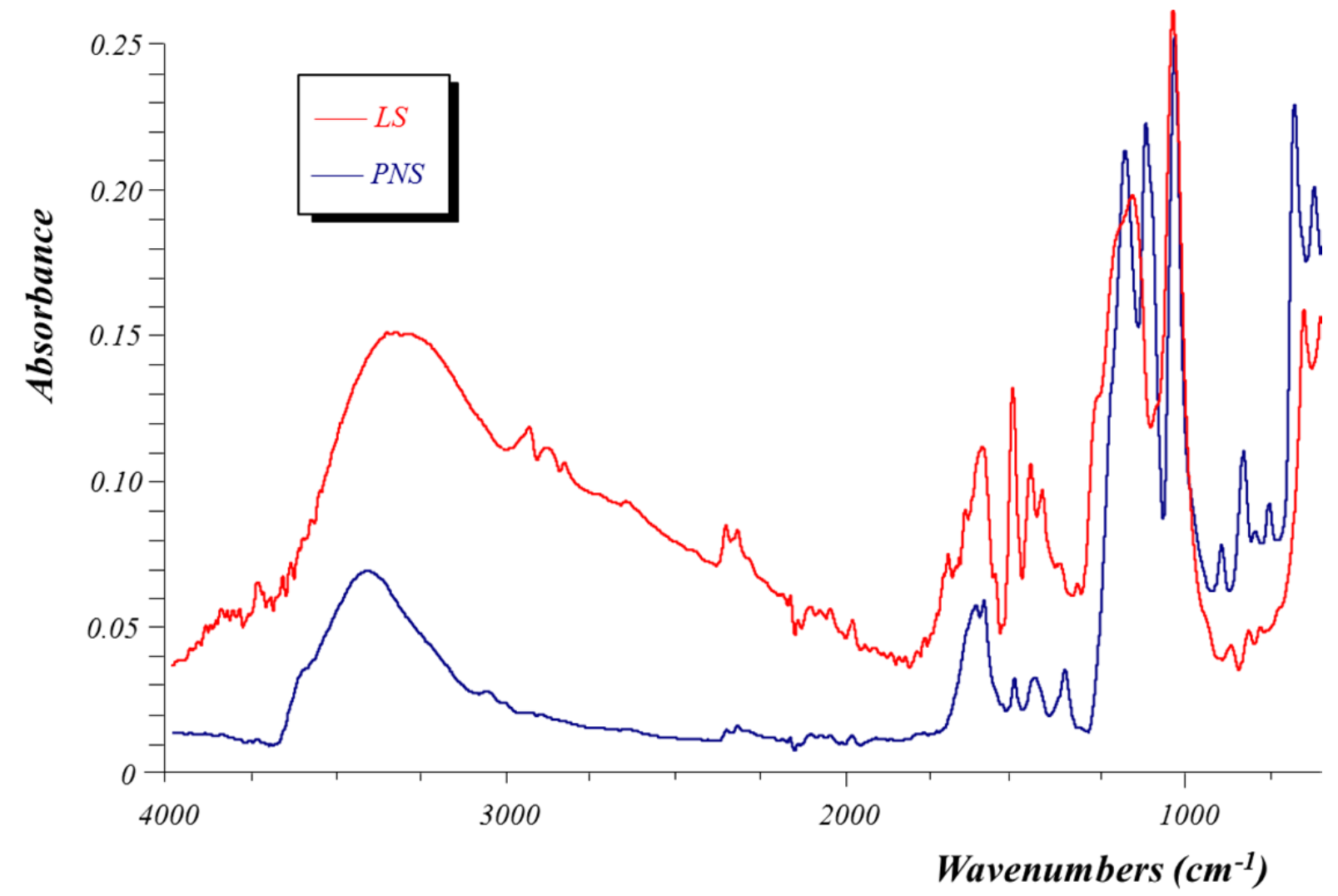

Figure 1. FTIR characterization of the two assayed superplasticizers. 


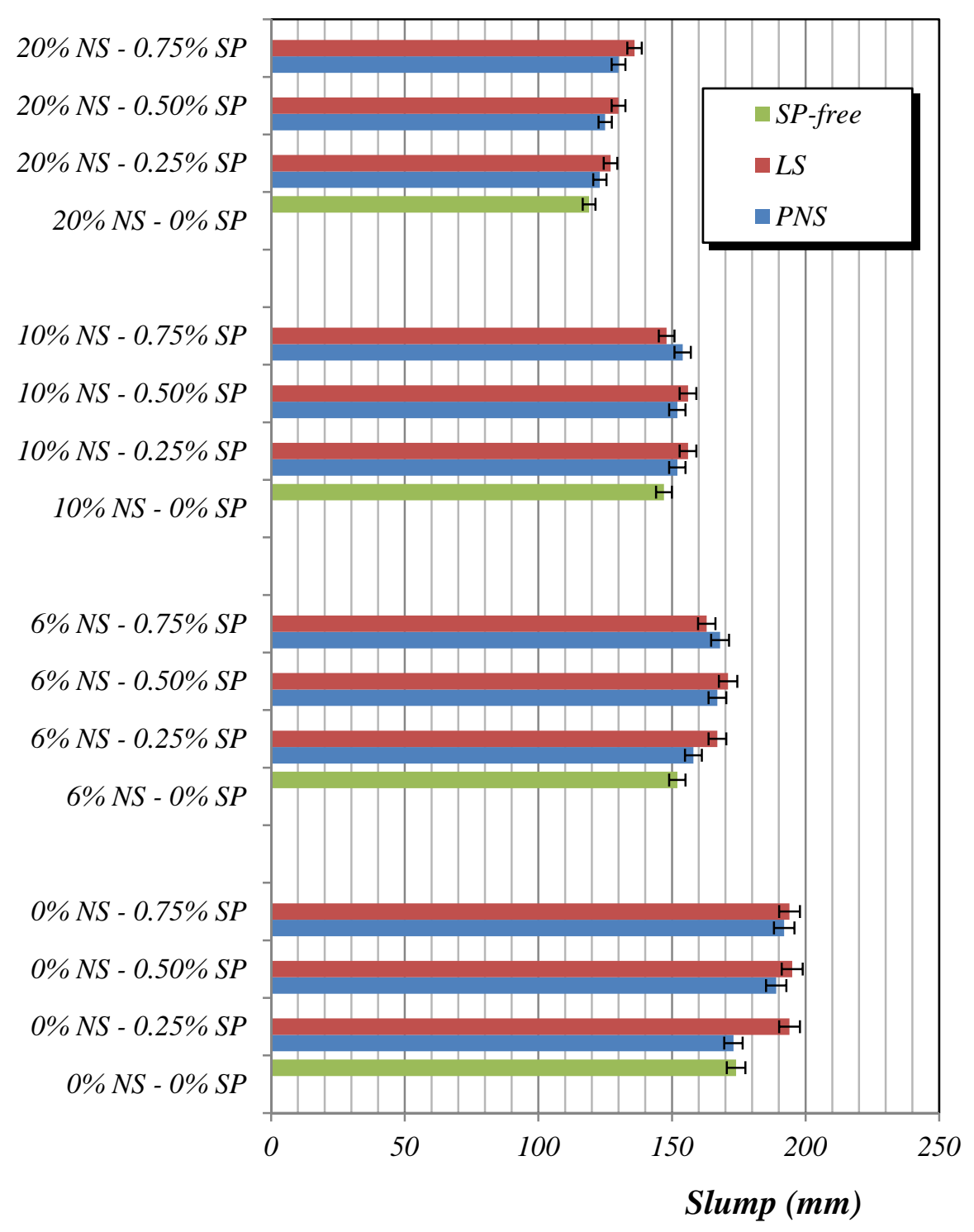

Figure 2. Slump values for different air lime pastes. 


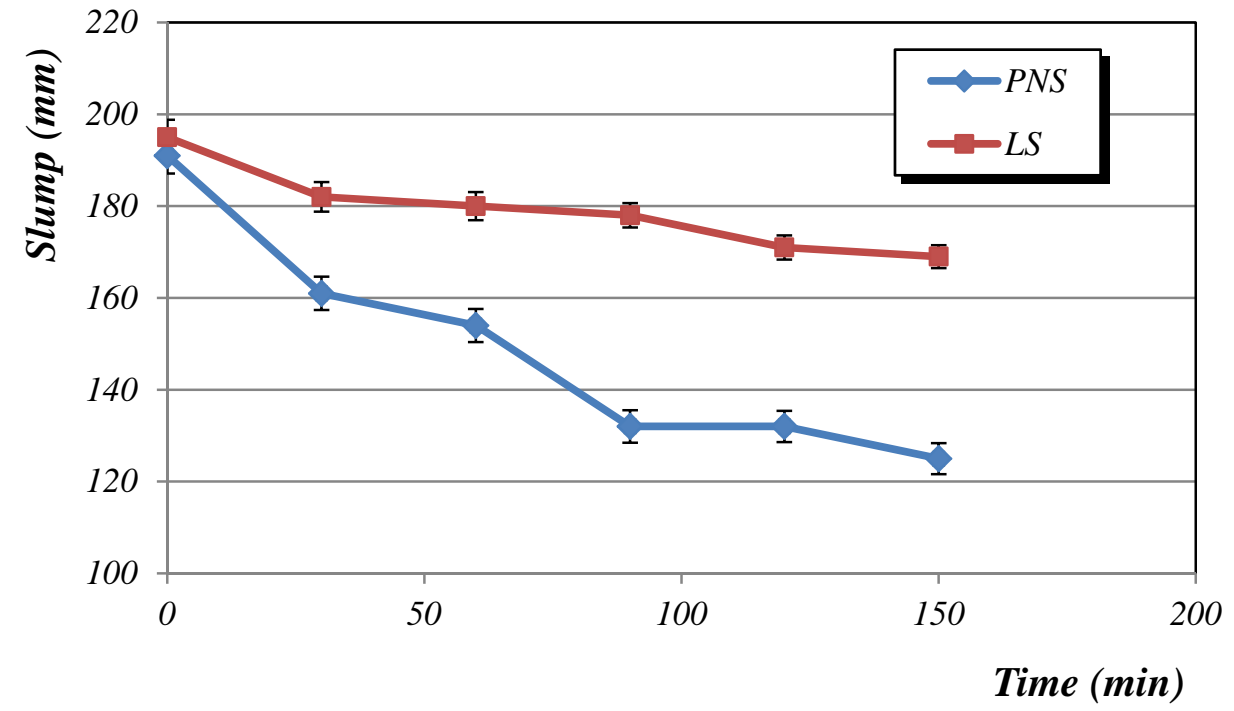

Figure 3. Slump loss over time in air lime pastes for PNS and LS additions.

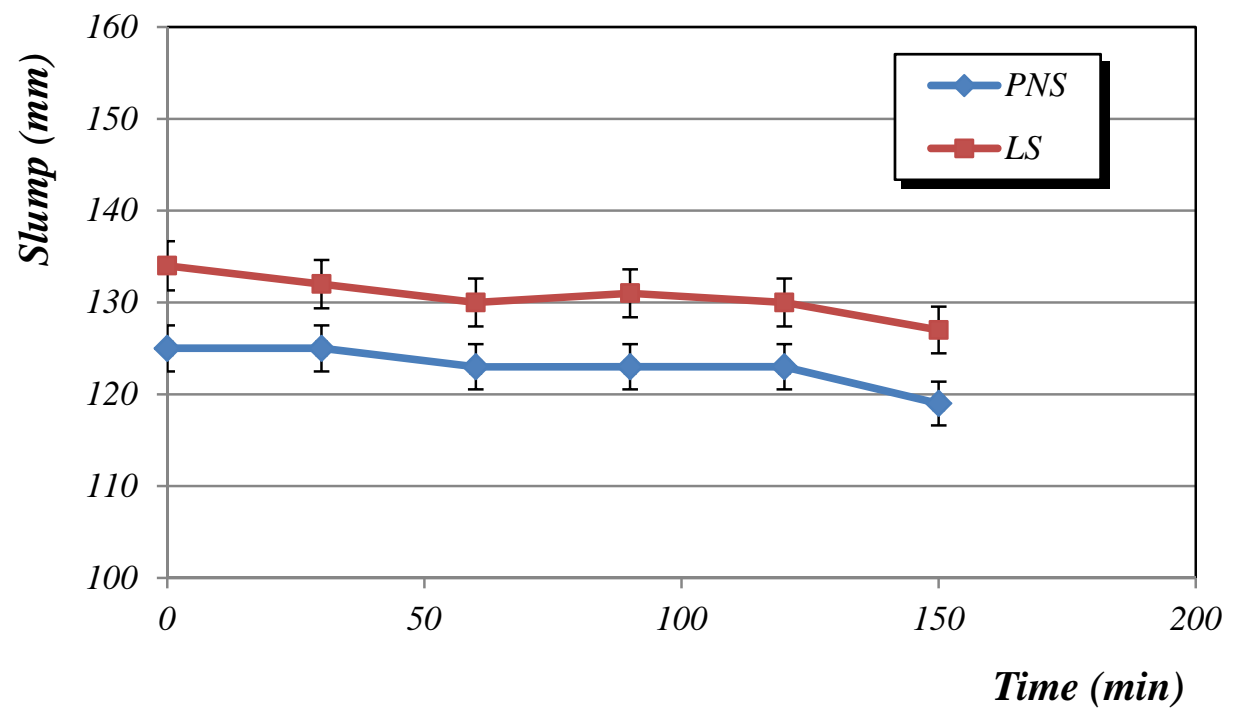

Figure 4. Slump loss over time in air lime + NS pastes for PNS and LS. 


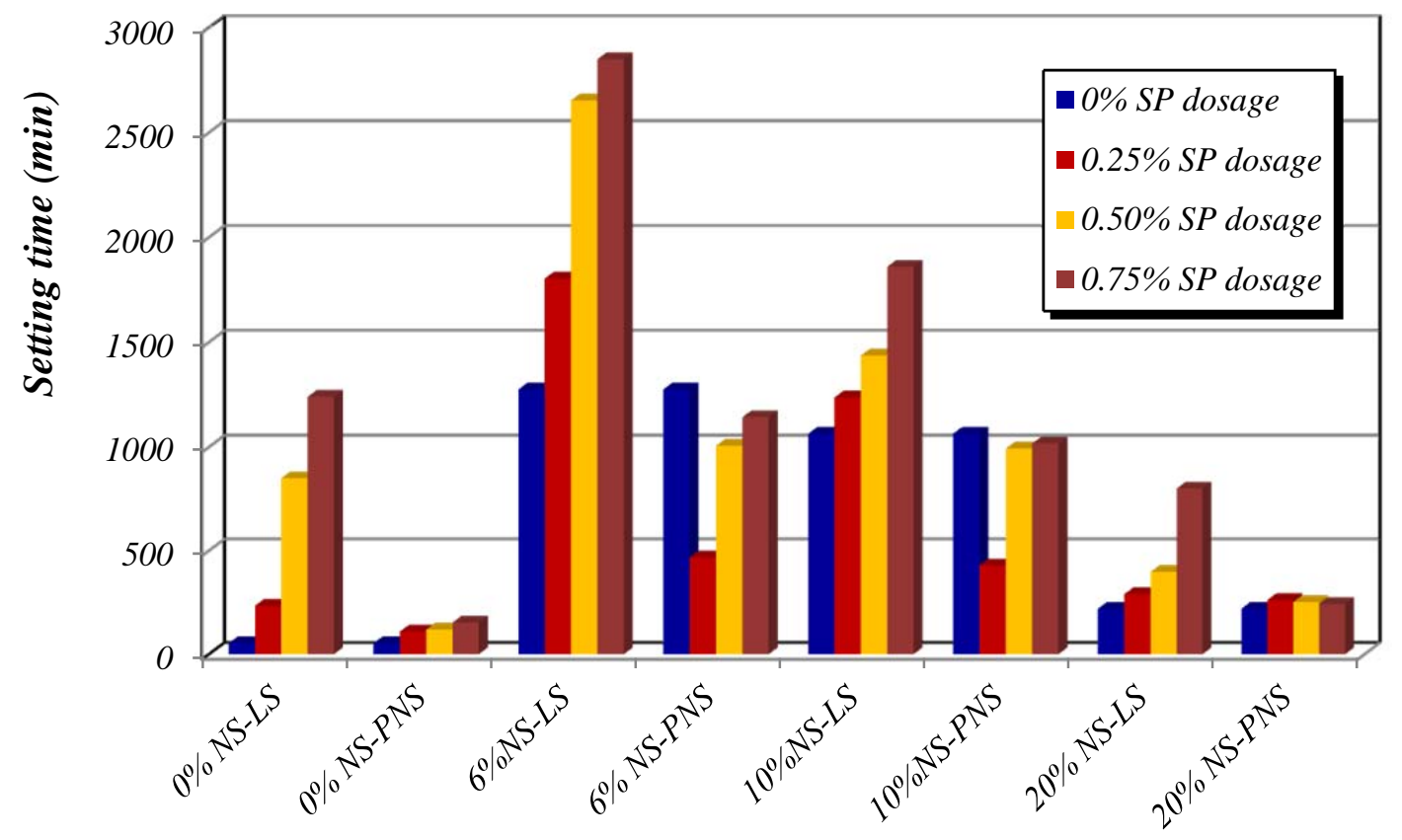

Figure 5. Setting times of samples as a function of different SPs dosages.

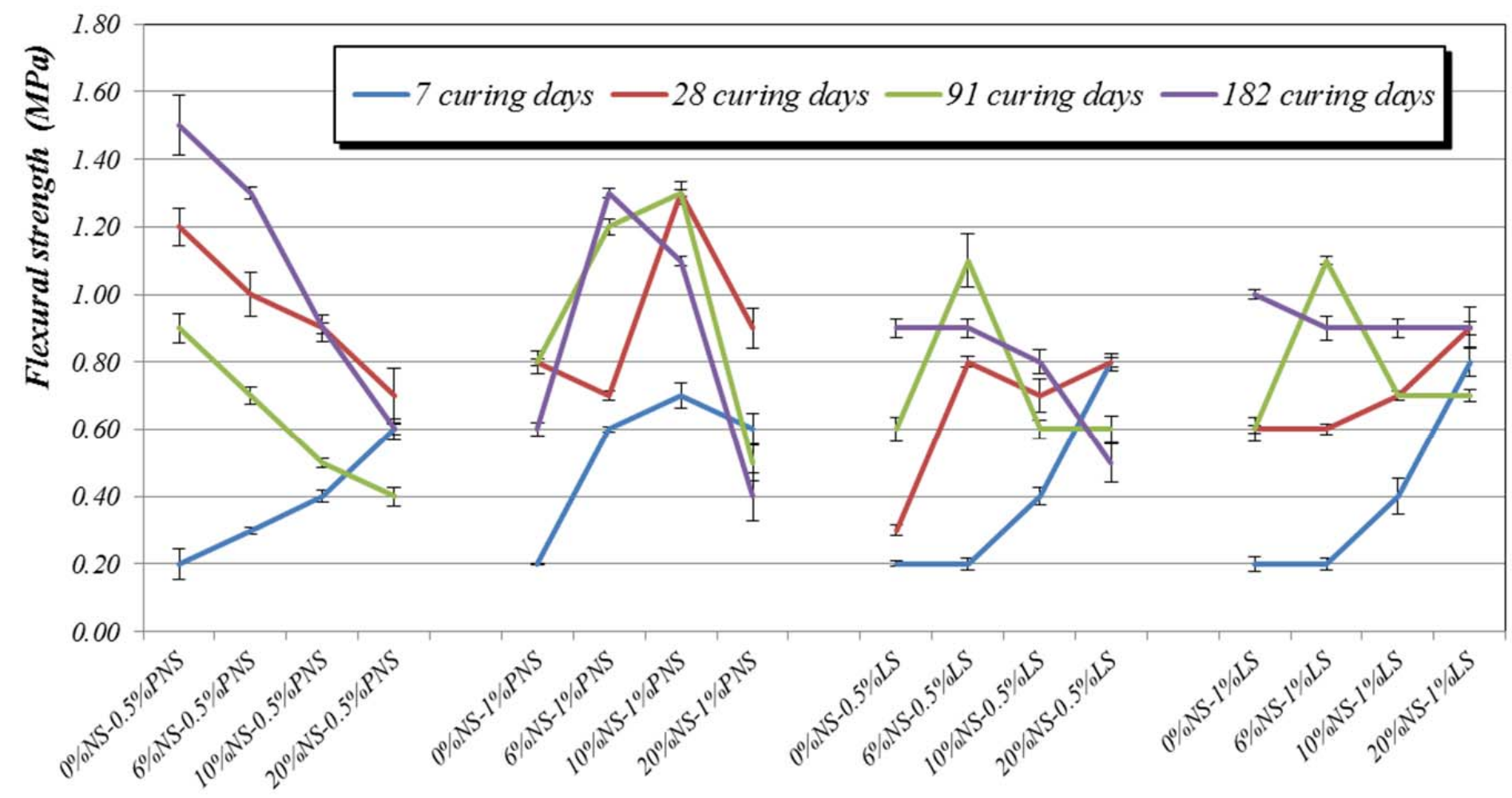

Figure 6. Flexural strength values vs. curing time. Left part: samples with PNS. Right part: samples with LS. 


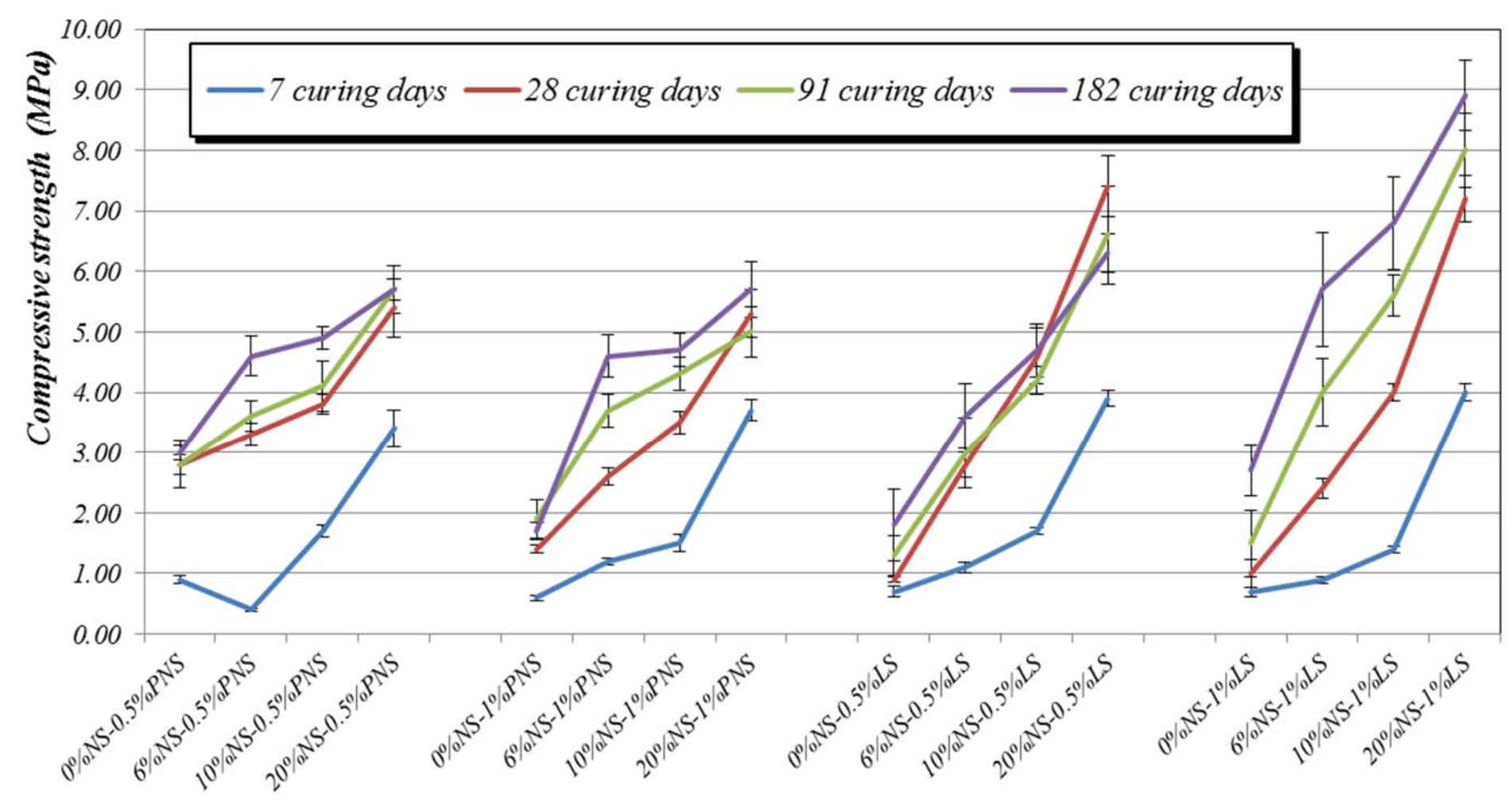

Figure 7. Compressive strength values vs. curing time. Left part: samples with PNS. Right part: samples with LS.

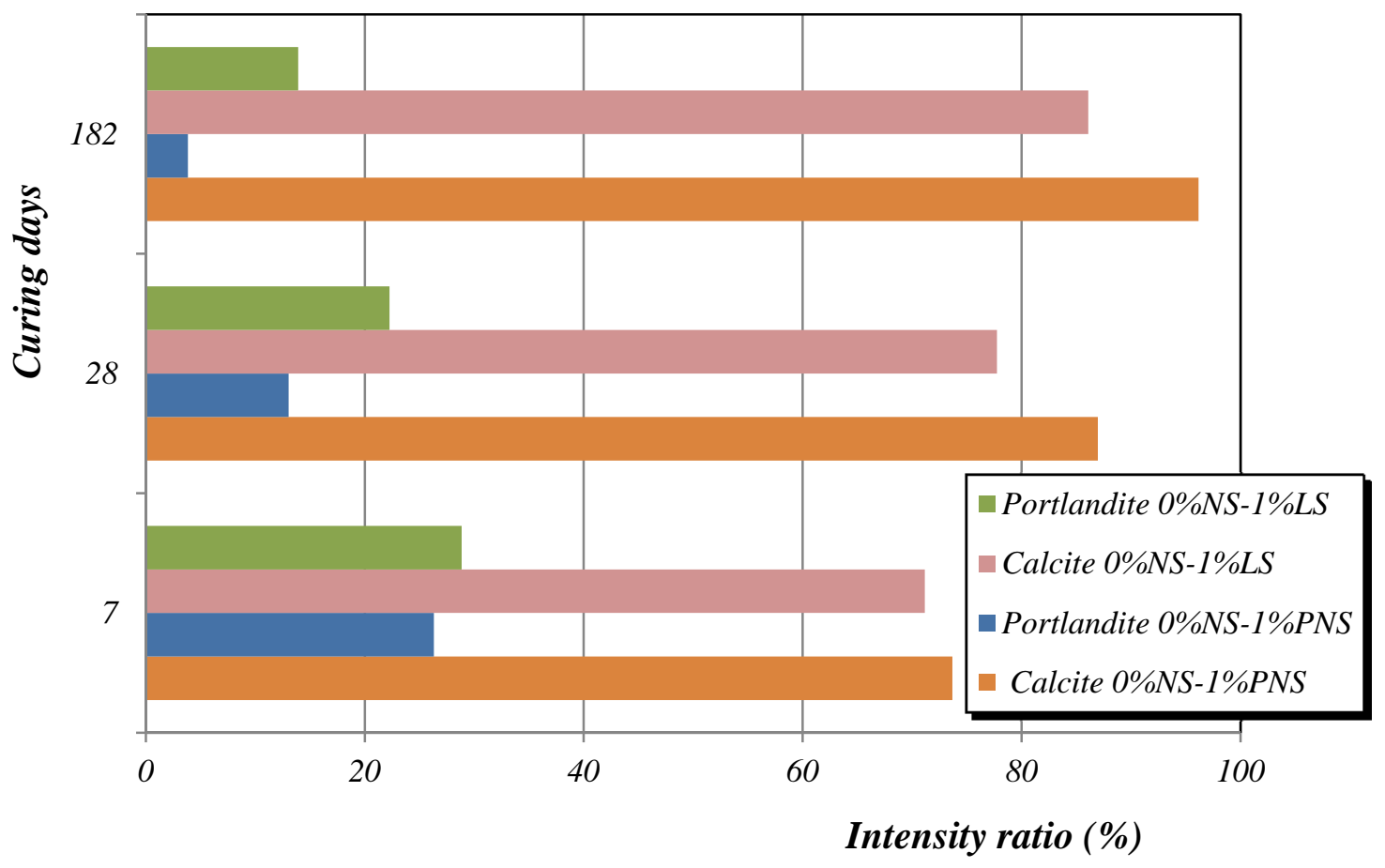

Figure 8. $\mathrm{XRD}$ intensity ratios of $\mathrm{Ca}(\mathrm{OH})_{2}$ (portlandite) and $\mathrm{CaCO}_{3}$ (calcite) for air lime mortars with 1\% PNS and LS, respectively, after 7, 28 and 182 curing days. 


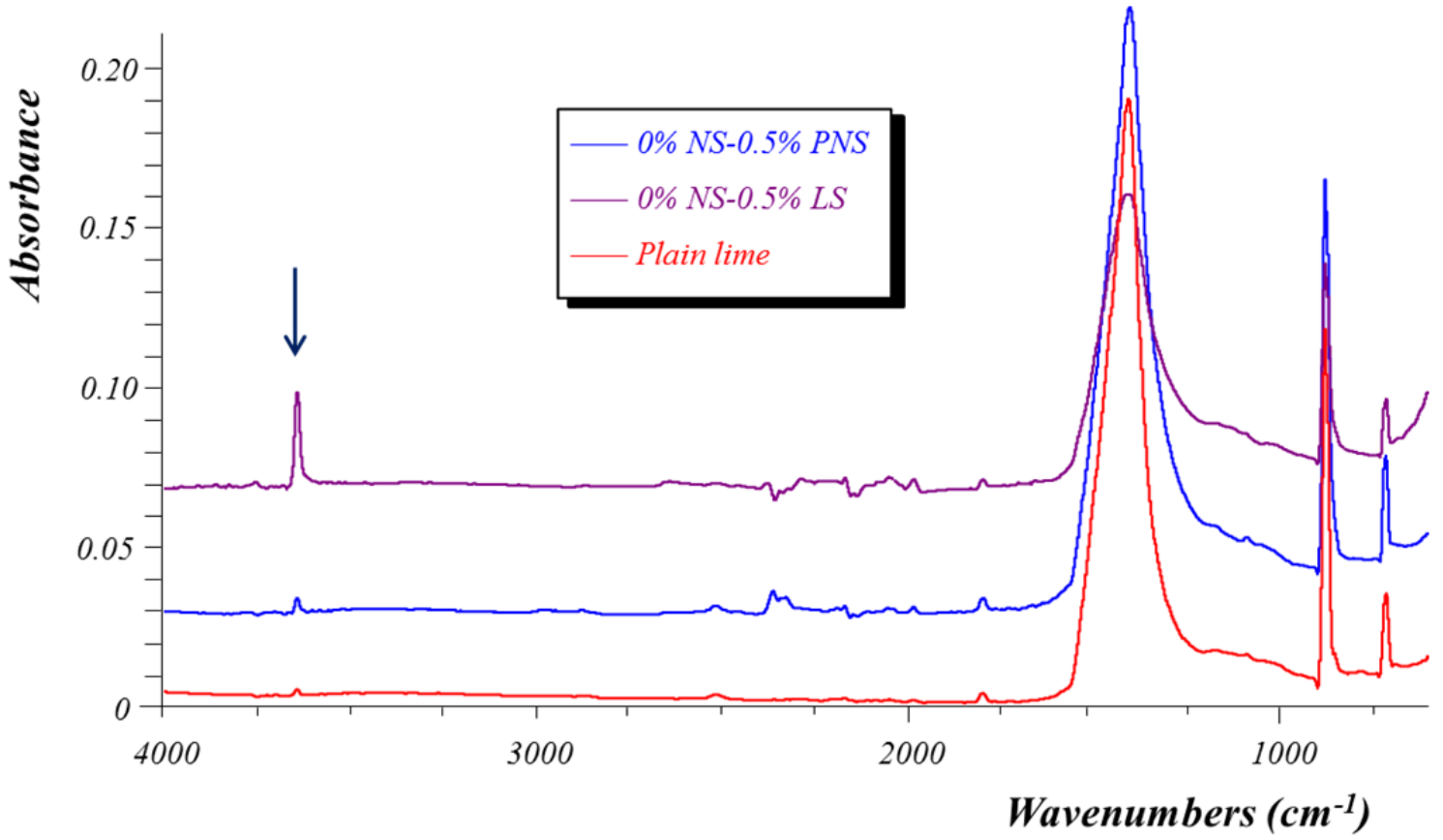

Figure 9. FTIR spectra of plain air lime, air lime with $0.5 \%$ of LS and air lime with $0.5 \%$ of PNS mortars (91 curing days). Black arrow denoted the sharp absorption band related to $-\mathrm{OH}$ groups.

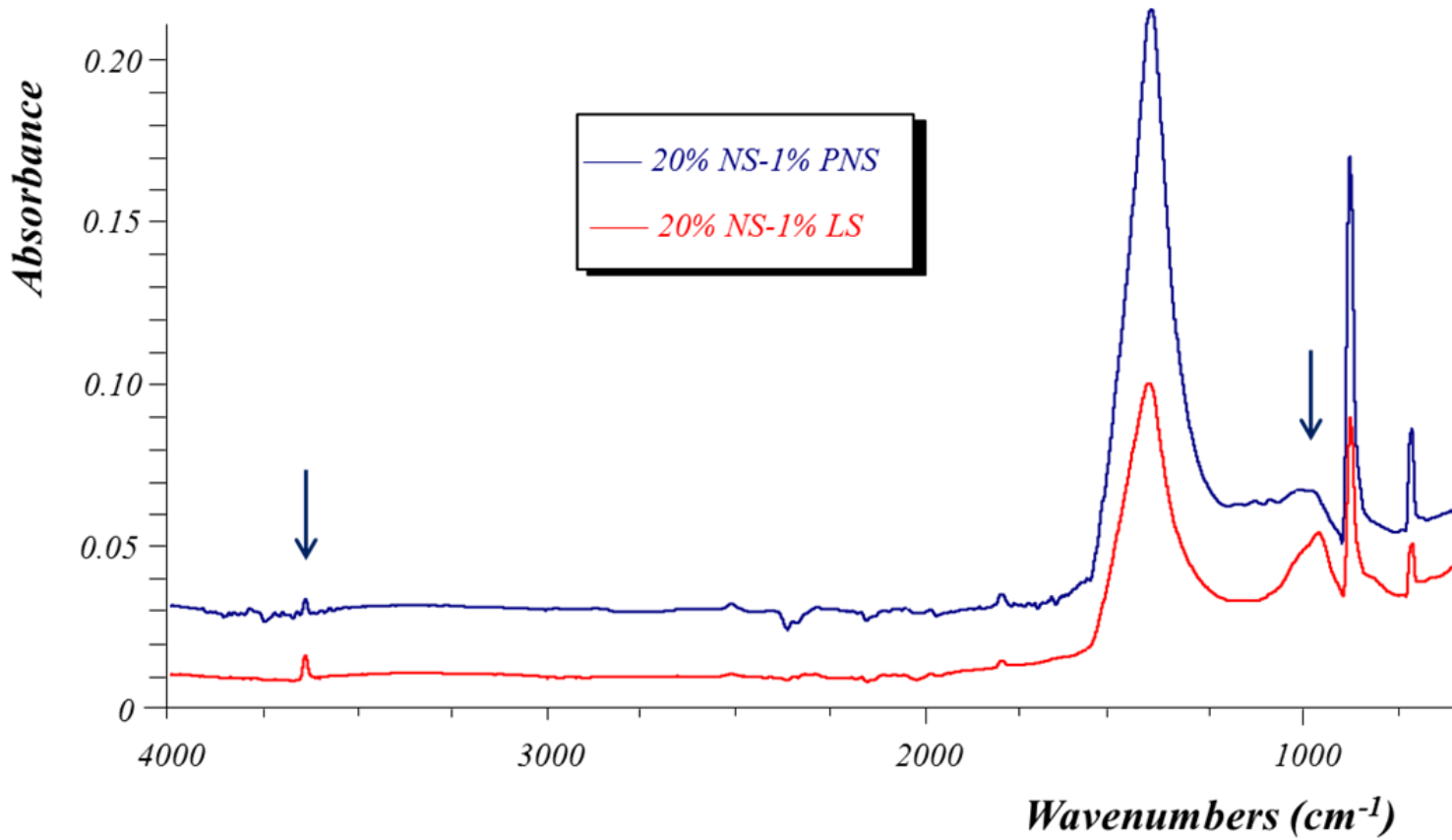

Figure 10. FTIR spectra of 20\% NS-air lime mortars with 1\% of LS and 1\% of PNS (91 curing days). Black arrows indicate the sharp absorption band related to $-\mathrm{OH}$ groups (ca. $3700 \mathrm{~cm}^{-1}$ ) and to the C-S-H (ca. $1000 \mathrm{~cm}^{-1}$ ). 


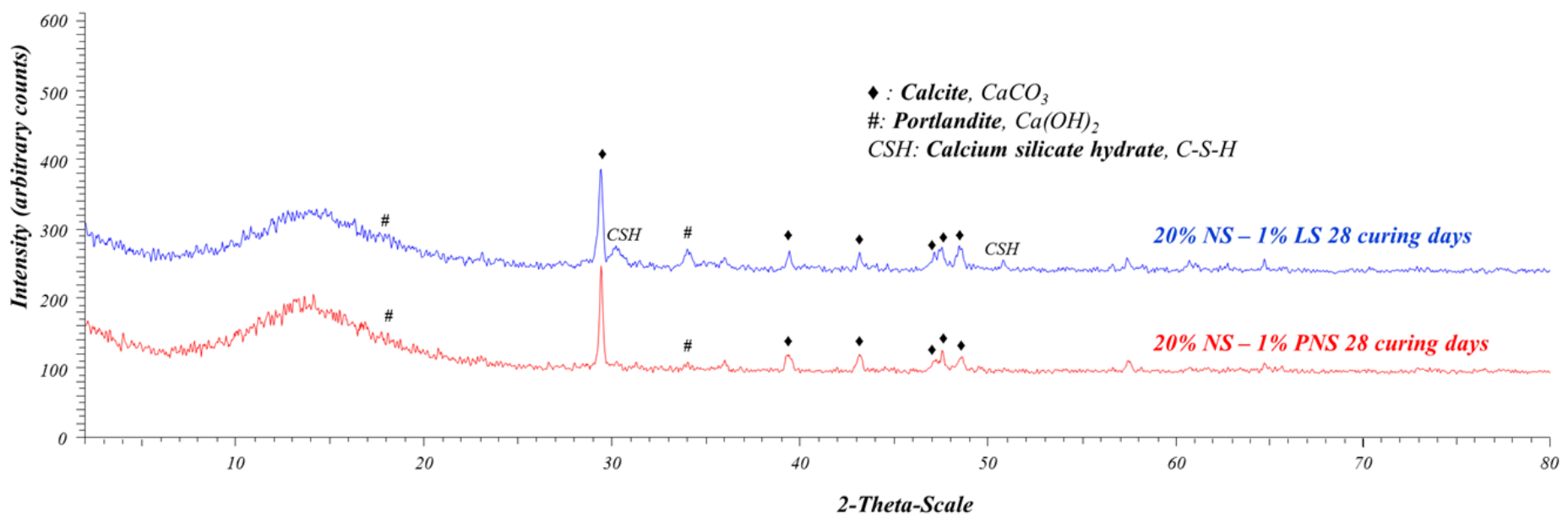

Figure 11. XRD patterns of samples with NS and either LS or PNS.
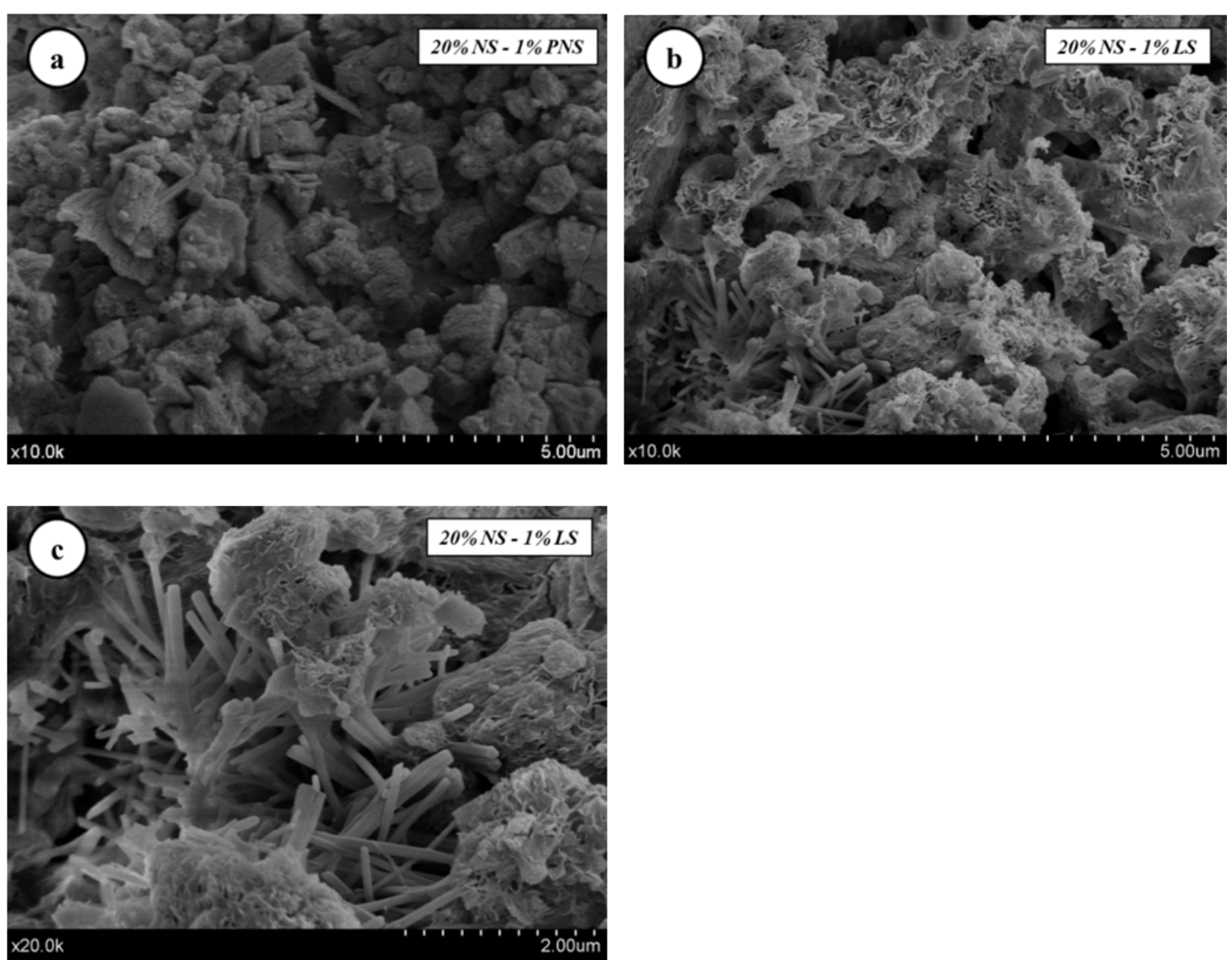

Figure 12. SEM micrographs of mortars after 182 curing days: a) PNS sample; b) LS sample; c) detail of LS sample. 

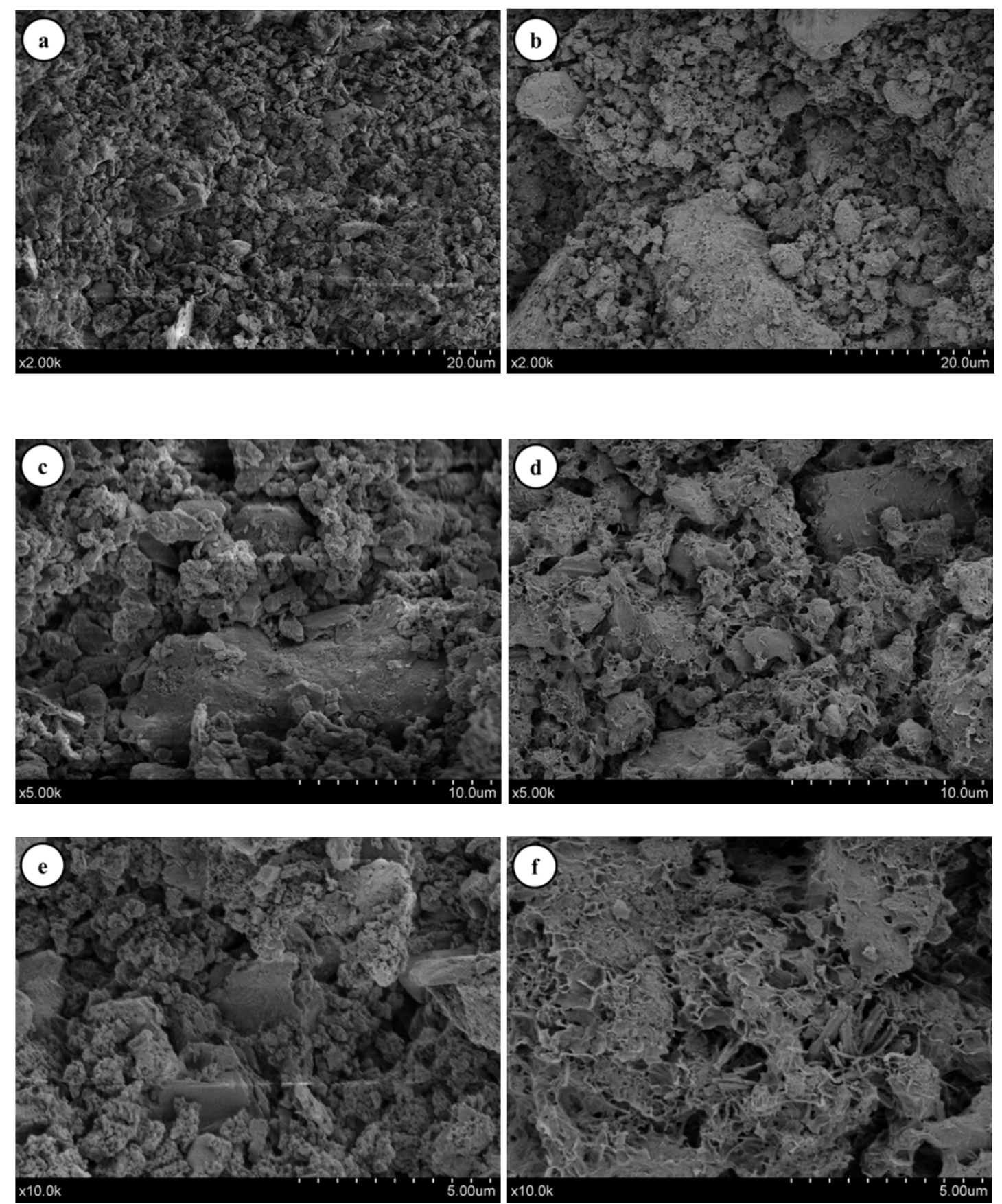

Figure 13. Comparative SEM examination between control samples at different magnifications: samples NS-free (a, c, e) and with NS (b, d, f). 

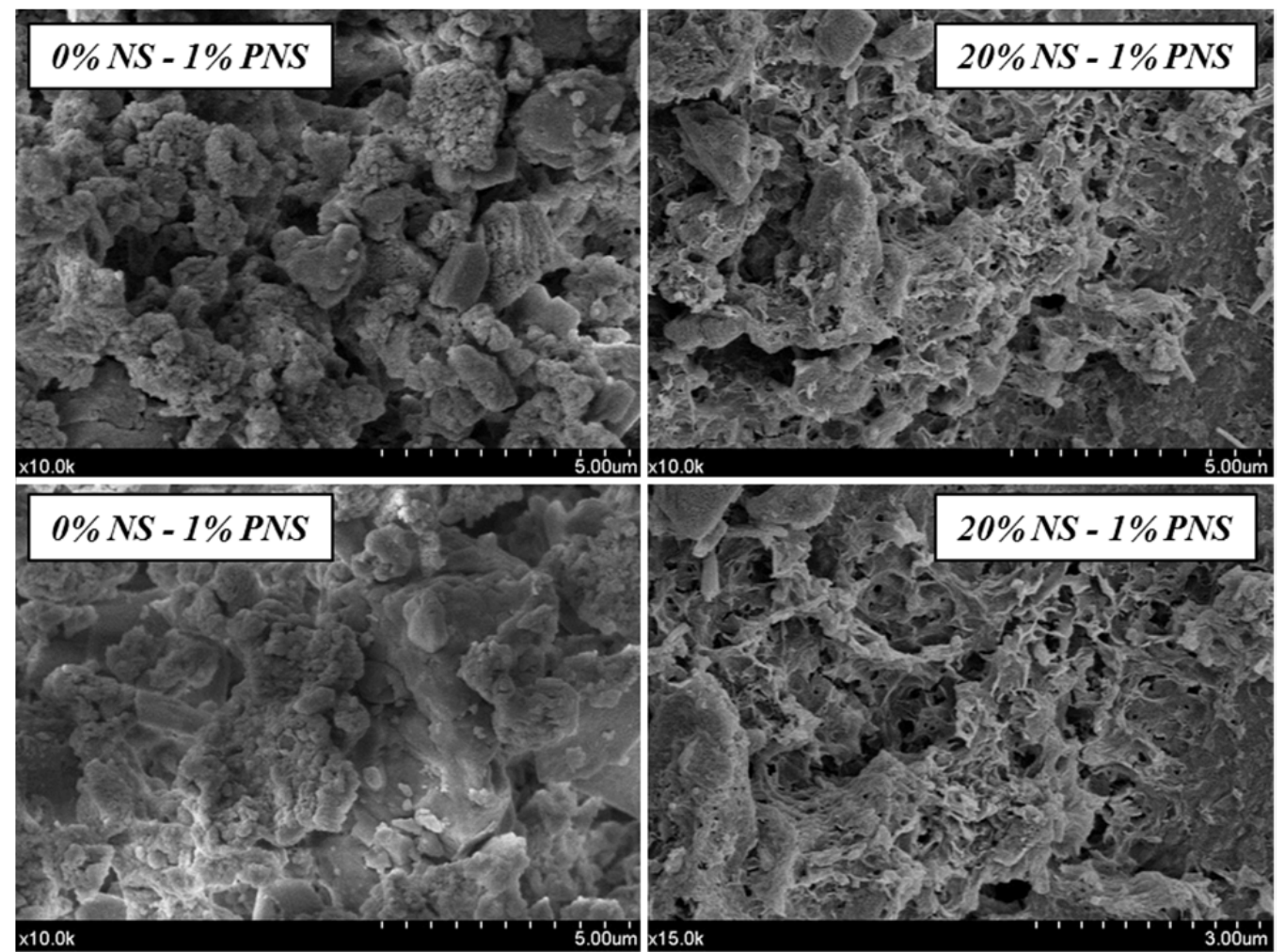

Figure 14. Microstructural examination by SEM of samples treated with PNS. Left part: samples without NS. Right part: samples with NS.

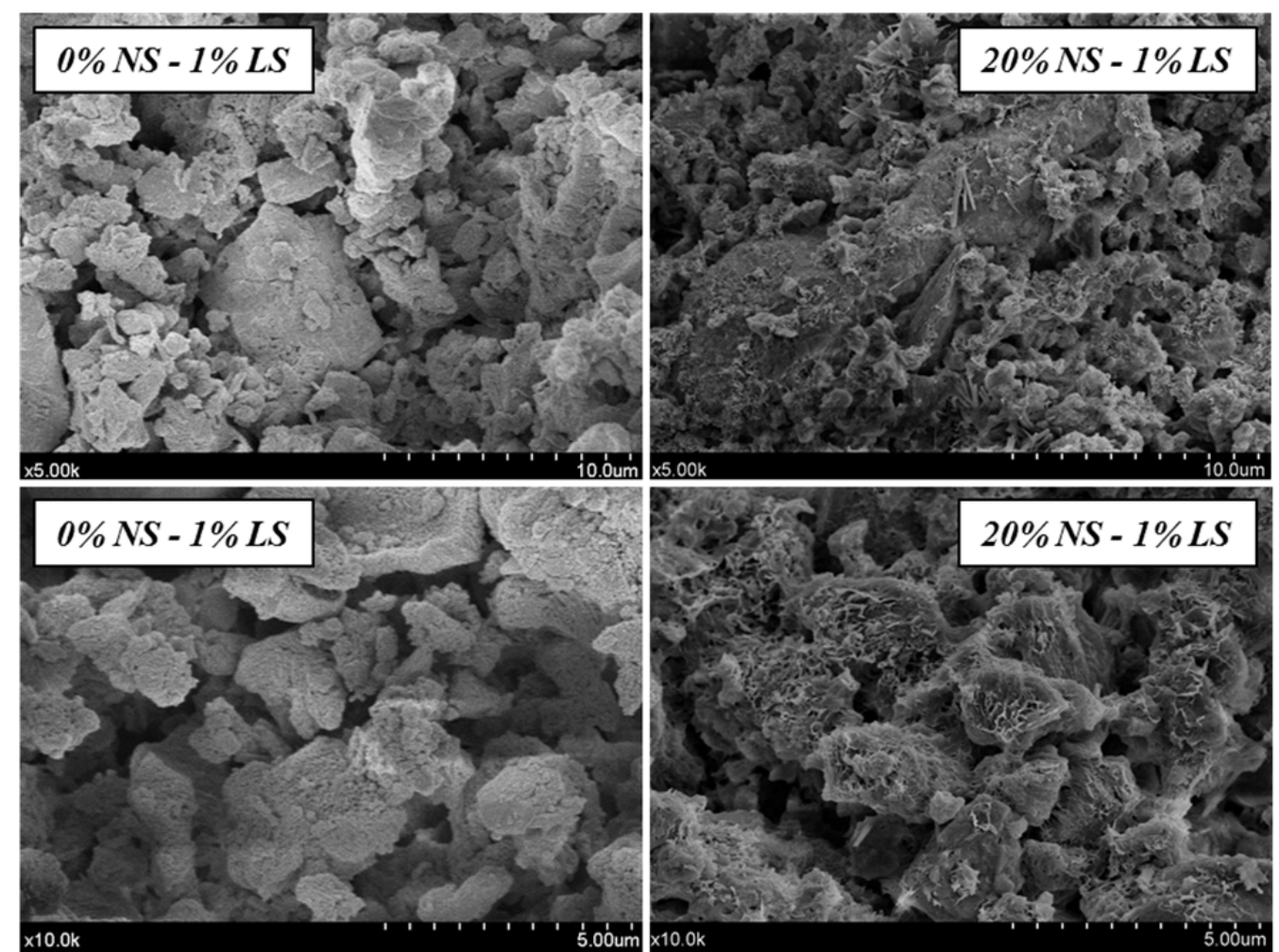

Figure 15. Microstructural examination by SEM of samples treated with LS. Left part: samples without NS. Right part: samples with NS. 


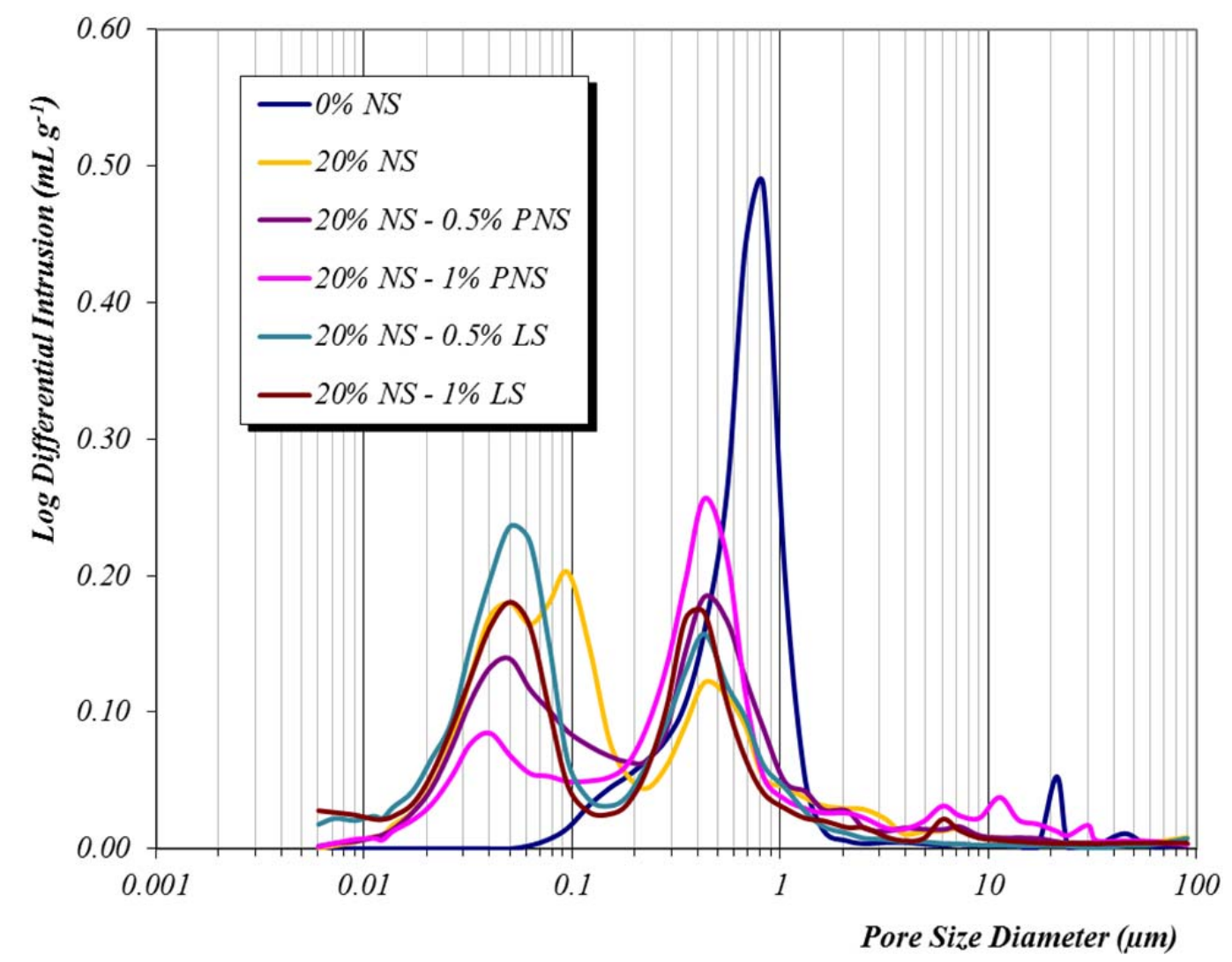

Figure 16. Pore size distributions of different mortar samples after 182 curing days.

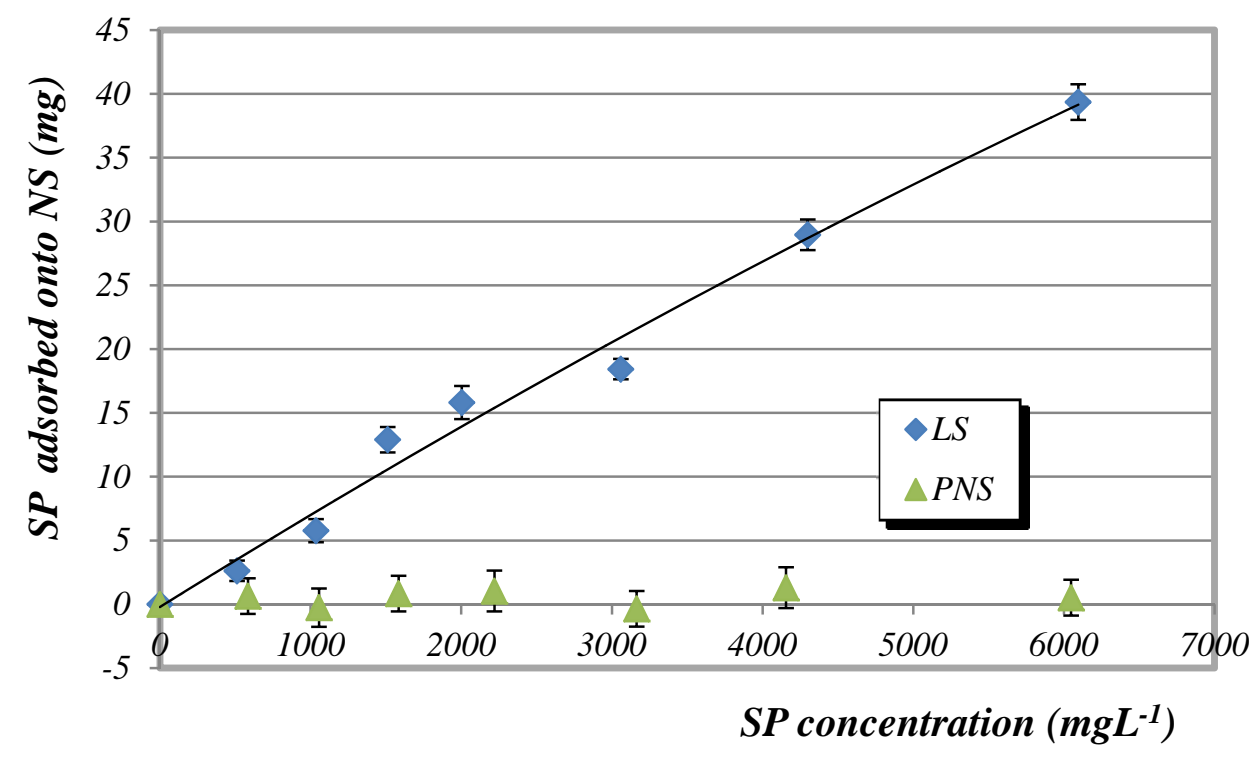

Figure 17. Adsorption isotherms of the superplasticizers assayed onto NS dispersions. 

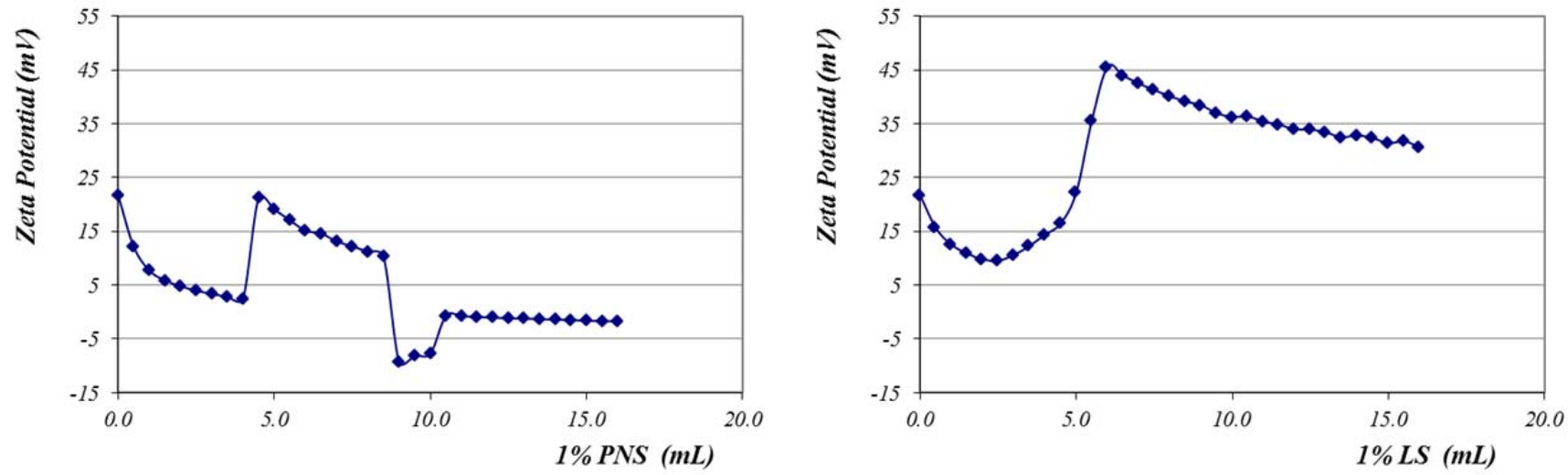

Figure 18. Zeta potential of pure air lime pastes titrated with a solution of superplasticizer (left curve: PNS; right curve: LS).
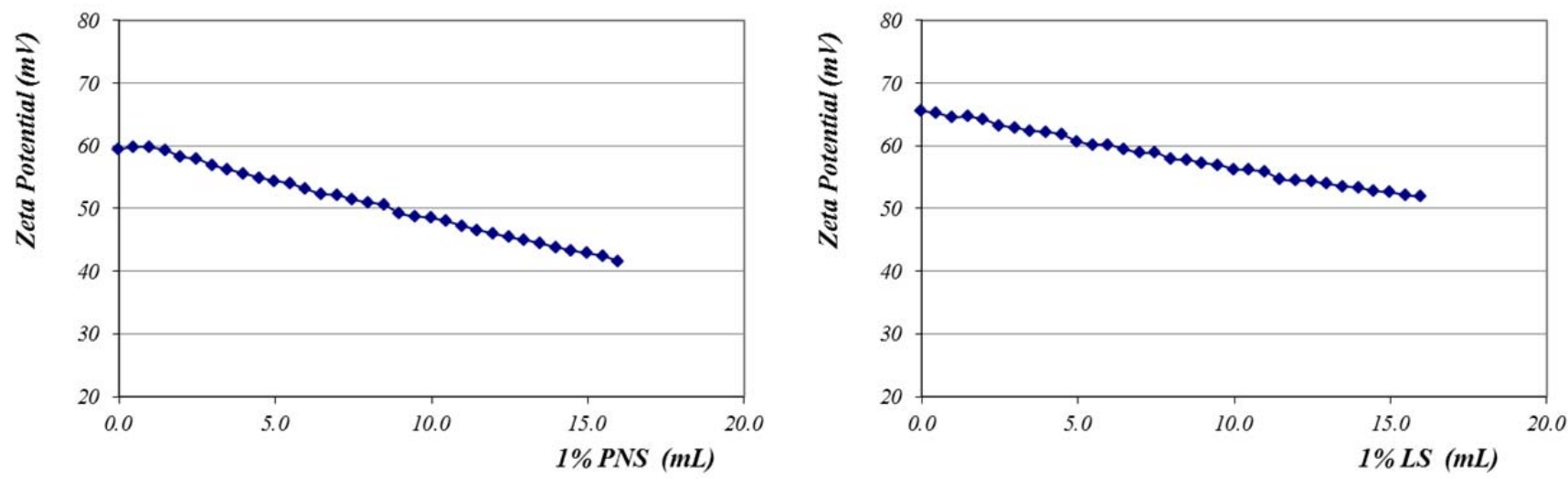

Figure 19. Zeta potential of NS + air lime pastes titrated with a solution of superplasticizer (left curve: PNS; right curve: LS).

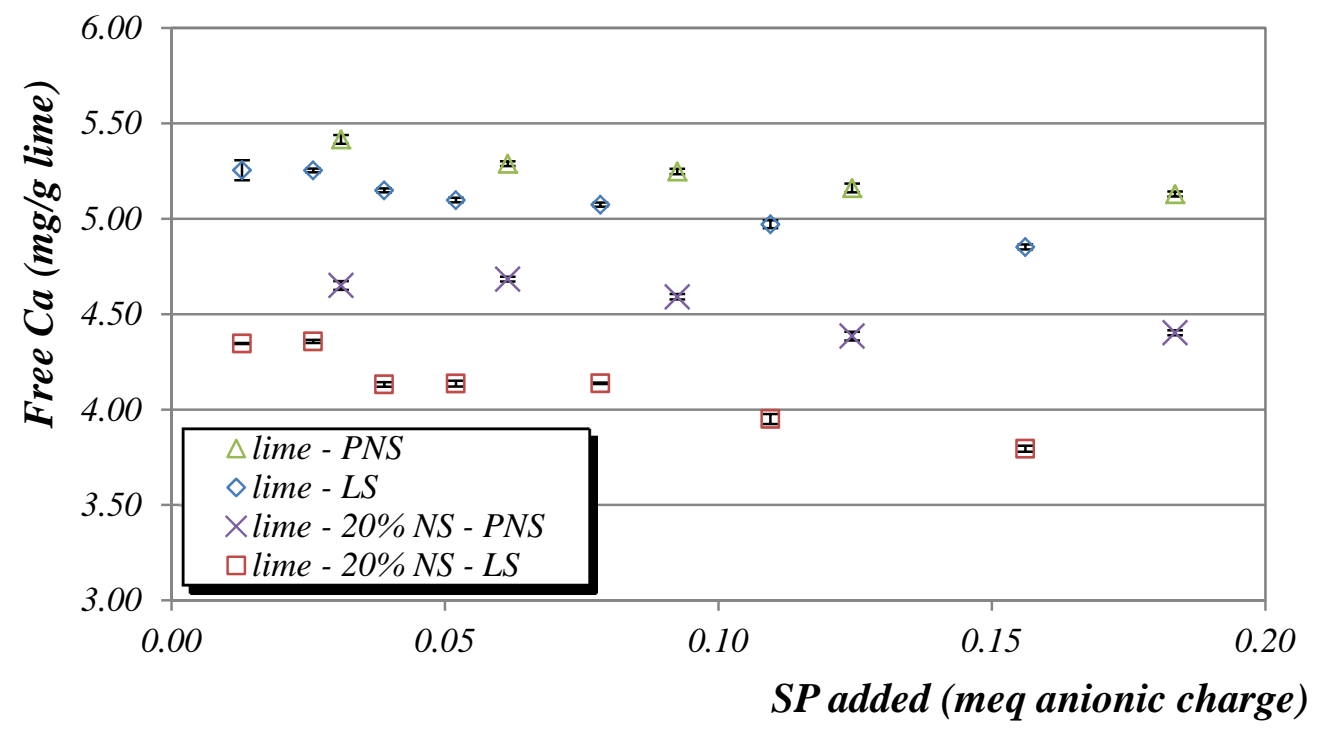

Figure 20. Free $\mathrm{Ca}^{2+}$ ions content in the pore solution vs. increasing dosages of SPs. 


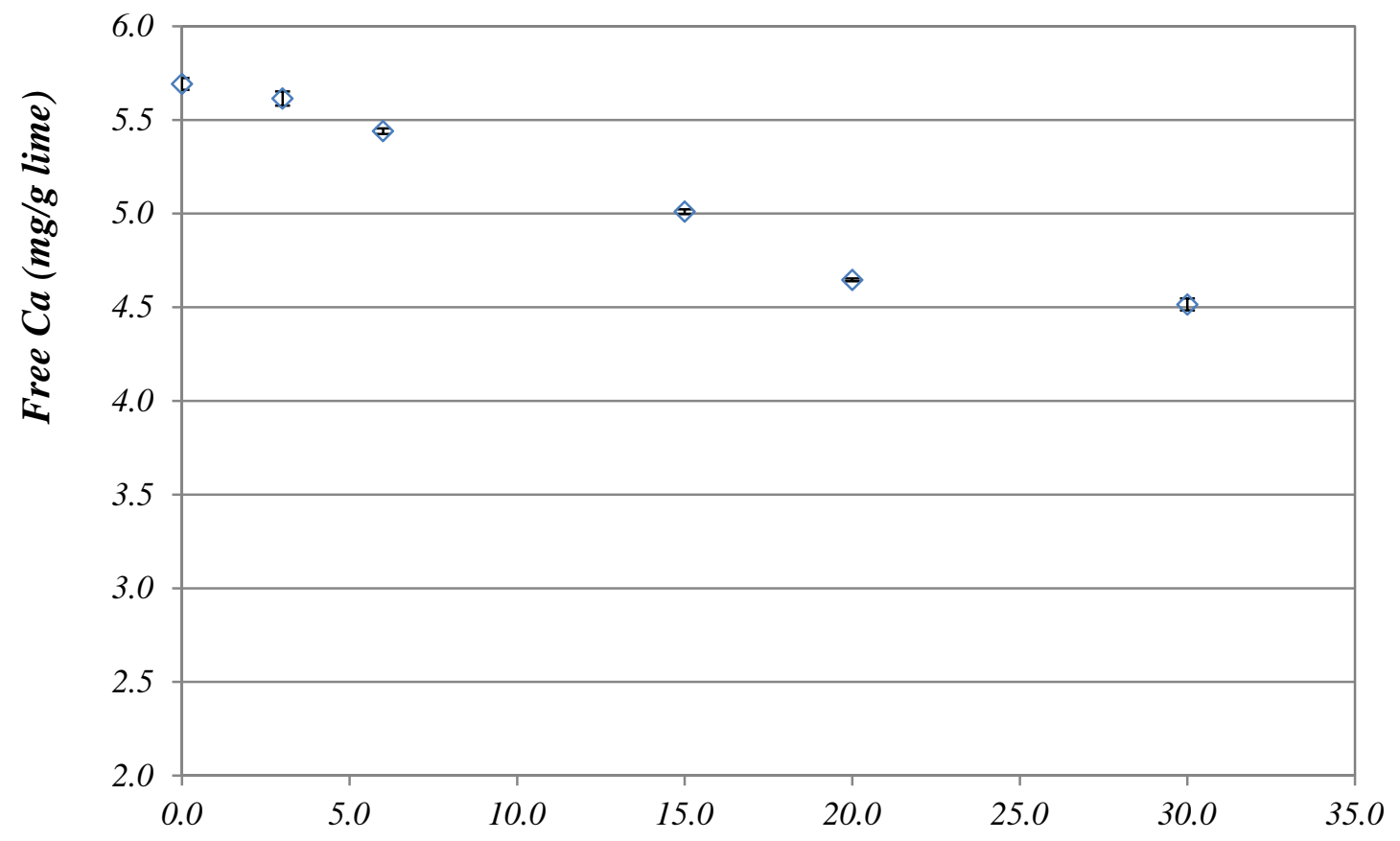

Nanosilica added (\%)

Figure 21. Free $\mathrm{Ca}^{2+}$ ions content in the pore solution vs. increasing percentages of NS.

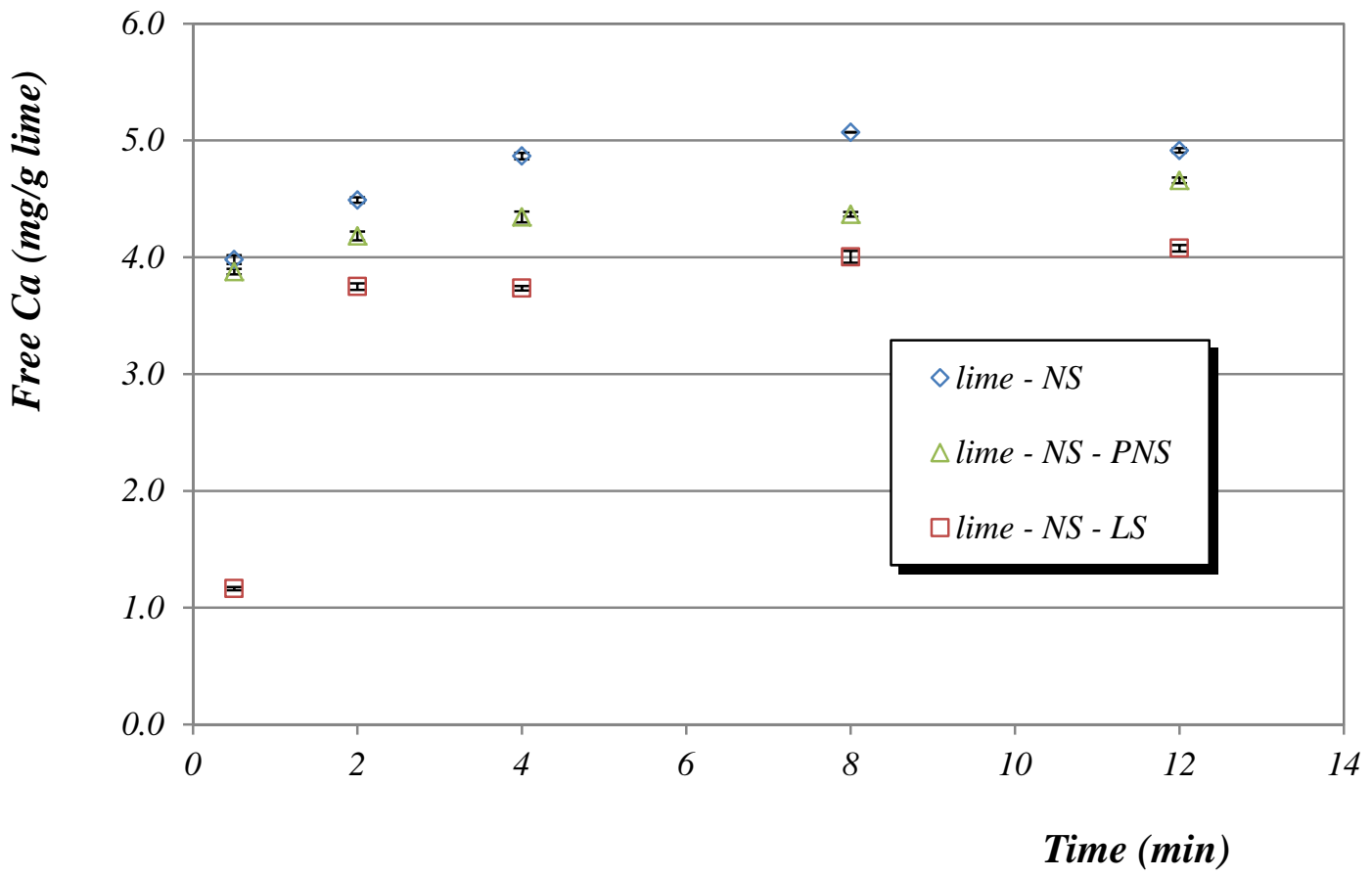

Figure 22. Free $\mathrm{Ca}^{2+}$ ions in the pore solution vs. time. 